University of Rhode Island

DigitalCommons@URI

Open Access Dissertations

2017

\title{
Investigating the Influence of Word Properties on Vocabulary Outcomes of At-Risk Kindergarteners
}

Chelsea A. Tucker

University of Rhode Island, chelseaanntucker@gmail.com

Follow this and additional works at: https://digitalcommons.uri.edu/oa_diss

\section{Recommended Citation}

Tucker, Chelsea A., "Investigating the Influence of Word Properties on Vocabulary Outcomes of At-Risk Kindergarteners" (2017). Open Access Dissertations. Paper 607.

https://digitalcommons.uri.edu/oa_diss/607

This Dissertation is brought to you for free and open access by DigitalCommons@URI. It has been accepted for inclusion in Open Access Dissertations by an authorized administrator of DigitalCommons@URI. For more information, please contact digitalcommons-group@uri.edu. 
INVESTIGATING THE INFLUENCE OF WORD

PROPERTIES ON VOCABULARY OUTCOMES OF AT-

RISK KINDERGARTENERS

BY

CHELSEA A. TUCKER

A DISSERTATION SUBMITTED IN PARTIAL FULFILLMENT OF THE

REQUIREMENTS FOR THE DEGREE OF

DOCTOR OF PHILOSOPHY

IN

PSYCHOLOGY

UNIVERSITY OF RHODE ISLAND 


\section{DOCTOR OF PHILOSOPHY DISSERATION}

OF

\section{CHELSEA A. TUCKER}

APPROVED:

Dissertation Committee:

\begin{tabular}{|c|c|}
\hline Major Professor & Susan Loftus-Rattan \\
\hline & Robert Laforge \\
\hline & Adam Moore \\
\hline & Nasser H. Zawia \\
\hline
\end{tabular}

UNIVERSITY OF RHODE ISLAND

2017 


\begin{abstract}
Direct and early vocabulary instruction is particularly important for children with low levels of vocabulary knowledge as they are at risk for later reading difficulties (Biemiller \& Slonim, 2001). It is recommended that, through direct and systematic instruction, these children be exposed to and learn what Beck, McKeown, and Kucan (2013) regard as Tier 2 vocabulary words, a subset of approximately 7,000 word families. Given that the words in this grouping differ widely across various word properties yet are taught using relatively fixed strategies, research inquiry surrounding word difficulty is warranted. Within the context of a Kindergarten vocabulary intervention study, the current study $(\mathrm{N}=853)$ investigated the relationship between two word properties, concreteness and syllable count, and Tier 2 vocabulary word learning outcomes over time, while controlling for differences in the length of time between instruction and assessment of vocabulary words. Results suggest that target word concreteness significantly predicts short-term and long-term learning outcomes when measured expressively, but not receptively; and that target word syllable count significantly predicts short-term learning outcomes when measured expressively, and short- and long-term learning outcomes when measured receptively. Implications for these results are discussed.
\end{abstract}




\section{ACKNOWLEDGMENTS}

I would first like to express my sincere appreciation of and gratitude to my Major Professor, Susan Loftus-Rattan, a constant source of expertise, encouragement, and enthusiasm. Her natural abilities to listen and inspire put her in a class of her own when it comes to guiding students. Susan has been a strong source of support for me since my undergraduate days and since then has supported me through both milestone accomplishments and in the face of those occasional logistical hitches, for which I am extraordinarily thankful.

Susan also made it possible for me to immerse myself in the important field of early vocabulary research by inviting me to become a research assistant on the highly regarded EVI project. Other project leaders (Mike Coyne, Sharon Ware) and research colleagues (including Sarah and Jenlyn) who played an important role in the success of Project EVI, ultimately helped make this dissertation possible.

I would like to extend heartfelt thanks to committee member Bob Laforge, an expert (and very patient) statistician who remained so clearly dedicated to supporting my work on this dissertation. Further, I would like to graciously thank Adam Moore and Alison Tovar, who gladly agreed to serve as committee members, for their commitment, time, encouragement, and assistance.

A very special mentor and friend to whom I owe profound gratitude is Dr. Jenlyn Furey, who provided endless support, advice, and laughs when they were needed the most since the days of Psychology Club. Another important mentor who has contributed to the completion of this dissertation is Dr. Lou Ruffolo. Lou has been an enormously supportive and encouraging internship supervisor throughout this process. 
I wish to especially thank my amazing and endlessly supportive family. Mom, Dad, Jet, Grammy, Opa, Jenn, Josh, Amy, Jeff, Greyson, Liz, and more, you are remarkable individuals who have provided unconditional love, support, and understanding, for which I am eternally grateful. 


\section{TABLE OF CONTENTS}

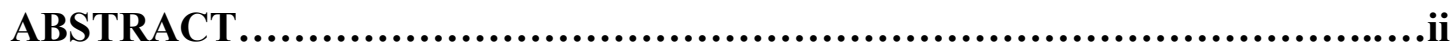

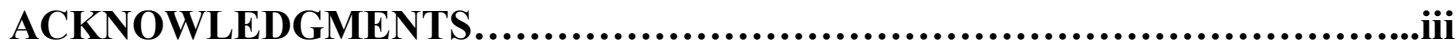

TABLE OF CONTENTS $\quad$..........................................................

LIST OF TABLES...............................................................vi

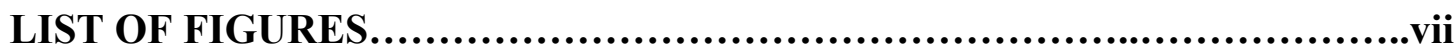

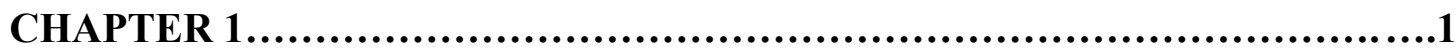

INTRODUCTION..........................................................

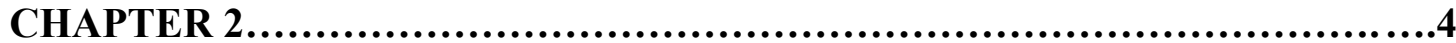

REVIEW OF LITERATURE ............................................

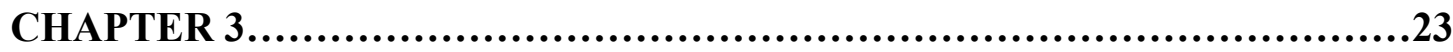

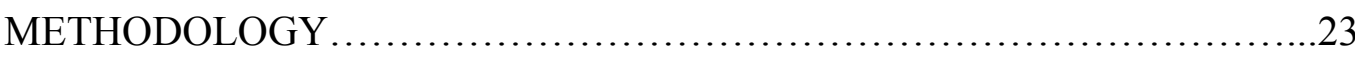

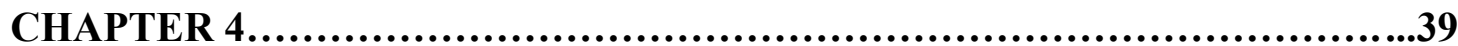

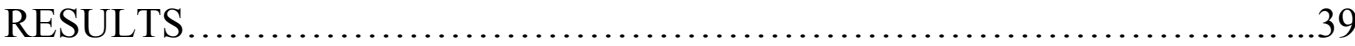

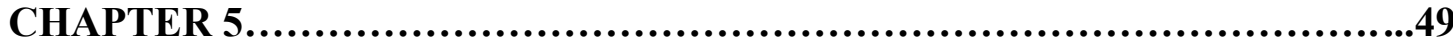

CONCLUSION .......................................................... 49

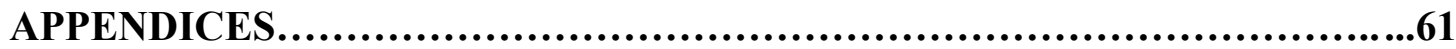

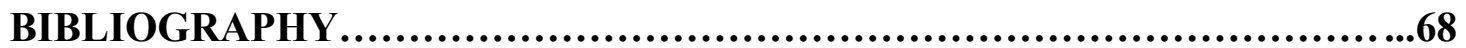




\section{LIST OF TABLES}

TABLE

PAGE

Table 1. Vocabulary Difficulty of Various Sources of Language ............................ .6

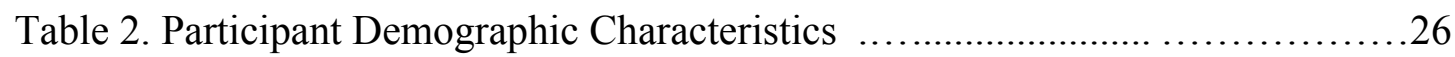

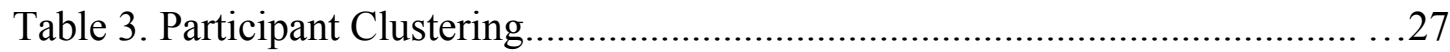

Table 4. Regression Table: Concreteness on Expressive Outcomes................43

Table 5. Covariance Parameter Estimates: Concreteness on Expressive Outcomes...44

Table 6. Regression Table of Concreteness on Receptive Outcomes.................44

Table 7. Covariance Parameter Estimates: Concreteness on Receptive Outcomes....45

Table 8. Regression Table of Syllable Count on Expressive Outcomes..............46

Table 9. Covariance Parameter Estimates: Syllable Count on Expressive Outcomes.47

Table 10. Regression Table of Syllable Count on Receptive Outcomes..............47

Table 11. Covariance Parameter Estimates: Syllable Count on Receptive Outcomes.47 


\section{LIST OF FIGURES}

FIGURE

PAGE

Figure 1. Weekly Tier 1 Instruction Overview.....................................27

Figure 2. Weekly Tier 2 Intervention Overview.............................................28

Figure 3. The Influence of Target Word Concreteness on Expressive and Receptive

Target Vocabulary Word Outcomes Over Time...............................................41

Figure 4. The Influence of Target Word Syllable Count on Expressive and Receptive

Target Vocabulary Word Outcomes Over Time................................................. 42

Figure 5. The Influence of the Instructional Sequence on Expressive and Receptive

Target Vocabulary Word Outcomes Over Time.............................................. 43

Figure 6. The Influence of Concreteness on Expressive and Receptive Target

Vocabulary Measures Over Time After Controlling for Instructional Sequence .....44

Figure 7. The Influence of Syllable Count on Expressive and Receptive Target

Vocabulary Measures Over Time After Controlling for Instructional Sequence .....45 


\section{CHAPTER 1}

\section{INTRODUCTION}

Early vocabulary remains a critical component in the development of reading skills and, therefore, a part of the foundation for school success (National Reading Panel, 2000). Early differences in exposure to oral language contribute to differences in vocabulary-learning opportunities, which result in some children beginning school with limited vocabularies (Hart \& Risley, 1995). Not only does this increase their risk for later reading difficulties but, without intervention, this gap in vocabulary knowledge is likely to widen over time (Biemiller \& Slonim, 2001; Chall, Jacobs, \& Baldwin, 1990).

Fortunately, evidence strongly supports the effectiveness of evidence-based explicit and extended vocabulary intervention in lessening this gap (Coyne, Kame'enui, \& Simmons, 2001; Loftus, Coyne, McCoach, Zipoli, \& Pullen, 2010). The general consensus is that the type of vocabulary words that warrant explicit and extended instruction are those that are reasonably challenging and likely to appear across domains. These types of words have come to be known as Tier 2 words, the optimal set of target vocabulary words wedged between basic, higher frequency words

(i.e., Tier 1) and topic-specific, lower frequency words (i.e., Tier 3) (Beck, McKeown, \& Kucan, 2013). Beck et al. (2013) estimate there to be 7,000 Tier 2 word families.

Focusing on these Tier 2 words rather than those of Tiers 1 or 3 helps to maximize instructional time by spending valuable time teaching only the words that students likely do not already know and those that are likely to be useful to know 
(Coyne, McCoach, Loftus, Zipoli, Kapp, \& 2009). Based on the estimate, however, that children would need to be explicitly taught 700 words per year through ninth grade in order to learn all the Tier 2 words, and that realistically only 400 words can be taught per year (Beck et al., 2013), children at risk for reading difficulties are further disadvantaged. With this challenging number of Tier 2 vocabulary words to teach, educators and children alike would surely benefit from strategies that then maximize their instructional time spent on these words.

One possible strategy that is under-researched is instruction informed by word difficulty. Word difficulty is suggested to guide teachers in their methods of word selection, selecting quantity/grouping of words, instructional strategies, and assessment (Laufer, 1990). Evidence suggests, for example, that properties such as word length and word imageability influence word-learning difficulty (Laufer, 1990; Leung, Silverman, Nandakumar, Qian, \& Hines, 2011; McDonough, Song, Hirsh-Pasek, Golinkoff, \& Lannon, 2011). Beyond the overt leveling of difficulty implied by the 3 Tiers (i.e., the words' difficulty increases as the Tiers increase), word difficulty within Tiers remains relatively unexplored (Wright \& Neuman, 2013; 2014). Despite the wide range in properties across the approximate 7,000 Tier 2 word families, current evidence-based instructional methods used to teach these words reflect an otherwise uniform approach to teaching each word.

In keeping with what current literature suggests about the need for further research surrounding word difficulty (Leung et al., 2011; Wright \& Neuman, 2013; 2014), the current study examines how two word properties (degree of word concreteness and syllable count) of Tier 2 vocabulary words taught in kindergarten, 
predict short- and long-term expressive and receptive target vocabulary word outcomes. Research inquiry into the degree to which at-risk children may struggle to learn Tier 2 words based on such properties is important for understanding how to best support their learning needs with implications for informing practice in the classroom. 


\section{CHAPTER 2}

\section{REVIEW OF LITERATURE}

\section{Importance of Vocabulary Skills}

Words are a basic and essential part of our culture. They are used as tools to express ideas, communicate with others, and learn information (Stahl \& Nagy, 2006). The greater the number of words in one's toolbox, the more equipped one is to precisely convey and advance ideas, as well as interpret incoming information. Mark Twain once wrote, "The difference between the almost-right word and the right word is really a large matter--it's the difference between the lightening bug and the lightening” (as cited in Stahl \& Nagy, 2006, p. 9).

For young children in particular, words seem to be a major key to success. Vocabulary skills, or overall knowledge of word meanings, have been reliably shown to be correlated with overall school achievement (Stahl \& Nagy, 2006; Wells, 1986). This is likely related to the long-established finding that early vocabulary knowledge is a critical component of later reading achievement (Anderson \& Freebody, 1981;

Davis, 1944; National Institute for Child Health and Development, 2000).

Correlational analyses have demonstrated the strong relationship between vocabulary and reading comprehension (Stanovich, Cunningham, \& Feeman, 1984; Tannenbaum, Torgesen, \& Wagner, 2006). In fact, kindergarten vocabulary skills have been shown to be predictive of reading skills in third grade and beyond (Scarborough, 2001). It has become clear that all children would benefit from acquiring strong vocabularies. 
Interest in methods that effectively bolster early vocabulary skills continues to grow in the field of education.

\section{Sources of Vocabulary}

Beginning early on in life, children acquire vocabulary knowledge through exposure to oral language (Hart \& Risley, 1995). The once widely held belief that children learn sufficient vocabulary knowledge through incidental exposure alone was maintained by the argument that there are simply too many words in the English language to teach directly to be able to make a difference in children's overall vocabulary knowledge (Beck et al., 2013). A problem with this argument is that the conversational oral language that young children are exposed to is among the least rich and varied of sources, especially when compared to books and newspapers (Hayes \& Ahrens, 1988). Table 1, which shows Hayes and Ahrens' (1988) analysis of various sources of vocabulary, suggests that conversation between two college-educated adults ranks the lowest in sources that offer exposure to rare words (i.e., not among the 10,000 most frequently used English words). As such, it is suggested that children do not learn sufficient vocabulary knowledge, which they will need to go on to become capable readers, through incidental exposure alone (Stahl \& Nagy, 2006). 
Table 1

Vocabulary Difficulty of Various Sources of Language Average Number of Rare Words (per 1,000)

Newspapers

68.3

Adult Books

52.7

Comic Books

53.5

Children's Books

30.9

Children's TV

20.2

Adult TV

22.7

Mr. Rogers

2.0

Cartoon Shows

30.8

Conversation between two college-educated adults

17.3

This table can be found in Hayes and Ahrens (1988, p. 401).

More recent evidence suggests that while there may be a relatively large number of words language users should know in order to read and comprehend efficiently, direct vocabulary instruction is possible, and more importantly, critical for reading achievement (Beck et al., 2013; Biemiller, 2001; Nation, 2001; Stahl \& Nagy, 2006). When this direct instruction is delivered explicitly and systematically, vocabulary instruction has been shown to lead to gains in vocabulary knowledge and, consequently, reading comprehension (NICHD, 2000; Stahl \& Fairbanks, 1986).

Importantly, research has shown that the intensity of this direct instruction should differ for students based on the level of their vocabulary skills upon school entry. Vocabulary skills in young children vary as a result of experiencing differences in exposure to oral language, with those differences being related to socioeconomic status (SES) background. Specifically, children from lower SES backgrounds have been found to arrive to school with significantly lower vocabulary skills, that is, know thousands fewer words, than their middle- and upper-SES counterparts (Hart \& Risley, 1995). English language learners (ELLs) are also put at risk as it can take up to five 
years for them to catch up to their peers' level of academic vocabulary (Cummins, 1994).

Research indicates that this gap in vocabulary knowledge grows increasingly more discrepant over time, a phenomenon known as the Matthew Effect in reading literature (Stanovich, 1986). Delivery of equal and high-quality instruction to all children, therefore, leaves many children with lower vocabularies at risk for having difficulty learning to read and unlikely to catch up to their peers (Biemiller, 2001; 2003; Biemiller \& Boote, 2006; Hart \& Risley, 1995). This vocabulary gap is suggested to grow over time due to the difficult nature of attempting to read rich texts without the necessary vocabulary knowledge. In turn, these lower vocabulary-skilled children lose out on opportunities to learn new vocabulary words that the rich texts have to offer. As such, they fall behind children who possess the vocabulary skills to take advantage of rich and varied texts (Stahl \& Nagy, 2006).

Once evidence revealed that children with low vocabulary knowledge have greater difficulty using context to interpret word meaning than their counterparts (Stahl, 1991), research began to strongly advise the use of differentiated vocabulary instruction to boost the skills of these at-risk children (Penno, Wilkinson, \& Moore, 2002). Differentiated instruction refers to the use of distinctive strategies for teaching students who differ from one another in terms of academic need, rather than "teaching to the middle," or employing one teaching strategy to academically reach all children in a given group (Subban, 2006). The strategies for employing differentiated instruction in the area of vocabulary have evolved. For example, at one time, Stahl and Shiel (1992) suggested that specifically those at risk for language and literacy 
difficulties should receive instruction around word-learning strategies and should be engaged in whole-class vocabulary discussions. Another recommendation for differentiating vocabulary instruction as a means of supporting at-risk children has included explaining more words during whole-class story time and providing examples to help with word comprehension during that story time (Robbins \& Ehri, 1992).

More recent evidence, however, builds upon these strategies and suggests the use of a multi-tiered approach to differentiated vocabulary instruction (Coyne, McCoach, Kapp, 2007), which corresponds to the response to intervention (RTI) model of intervention. This approach features high-quality whole-class instruction, such as embedded and extended instruction through storybook reading to the class, in addition to more intensive, small-group instruction (i.e., intervention) for at-risk children, that together can help to "offset pervasive Matthew effects in vocabulary development" (Coyne et al., 2007, p. 87). Fortunately, delivering evidence-based vocabulary intervention to the at-risk children beyond what is delivered in a wholeclass setting has been shown to be important in diminishing the gap (Biemiller, 2003;

Cuticelli, Coyne, Ware, Oldham, \& Loftus Rattan, 2015; Coyne et al., 2001; Loftus et al., 2010). Having established the critical need for evidence-based vocabulary instruction, the subsequent sections discuss the elements of that instruction.

\section{Word Selection}

What makes vocabulary learning unique, relative to other reading skills, is that there is no developmental sequence to learning words; that is, 'our brains are not wired to acquire words in any given sequence' (Beck et al., 2013, p. 20-21). It may seem, 
then, as if there is great leeway when it comes to the selection of vocabulary words. The English language comprises more than 600,000 words (excluding many words with prefixes, suffixes, and words since developed in science and technology) (Crystal, 1995). With this range of options and no single set of vocabulary words universally designated specifically for kindergarten instruction, it is unsurprising that vocabulary word selection has garnered much attention (Leung et al., 2011).

Not just any words will do, of course, as teaching vocabulary words that are too easy or too difficult for a child is not an efficient use of instructional time. Several different approaches developed in recent years help educators to identify suitable vocabulary words targeted for direct instruction in the early grades. Notably, these frameworks suggest choosing vocabulary words largely based on their frequency; the premise being that the greater frequency of a word's appearance in texts of a given level, the more useful it is presumed to be for students of a given level to learn its meaning (Beck, et al., 1987; Hiebert, 2005; Nation, 2001).

There are approaches that offer procedures for identifying specific target words, such as that proposed by Hiebert (2005), who recommends teaching the foundational words that frequently occur within curricula in fifth grade and beyond as a way to prepare students for later encounters with more complex text. Other approaches offer criteria for choosing words such as those by: Nation (2001), who proposed targeting high frequency words, low frequency words, academic words, and technical words for direct instruction; Stahl and Nagy (2006), who recommended selecting words that are high in frequency and utility; and Beck, McKeown, and 
Omanson (1987), who proposed a three-tiered framework for conceptualizing vocabulary words more or less by frequency.

The three-tiered framework recommended by Beck et al. (1987) is widelyaccepted as a means for selecting vocabulary words and it is the framework used in the current study. It is important to note that this framework does not offer specific word lists that neatly correspond to each tier; rather, it is a "heuristic for categorizing words" that avoids excluding what may be a suitable vocabulary word in a given classroom but not as relevant in another (Beck, McKeown, \& Sandora, 2012, p. 19). Tier 1 is conceptualized as the basic, high-frequency/high-utility words that children are likely to already be familiar with at school entry such as my, water, because, and want. Next, Tier 2 words are more sophisticated and less frequently used compared to those in Tier 1, but are used across domains, such as improvise, admit, morsel, and chaos. Lastly, Tier 3 words are conceptualized as words that are low frequency and domain-specific such as chromosomes, circumference, filibuster, and epidermis. The Tier 2 words are considered ideal target vocabulary words for students in Kindergarten because they likely are not yet familiar with them, but would likely encounter them in multiple settings.

It is estimated that there are approximately 7,000 Tier 2 words (Beck et al., 2013). In order for children to learn all the Tier 2 words, educators would need to explicitly teach 700 words per year through ninth grade. Two problems with this are that ideally, children should learn these words well before reaching ninth grade and that realistically, only approximately 400 words can be taught per year using the current instructional methods (Beck et al., 2013). Unless a more efficient instructional 
method is developed, children at risk for reading difficulties are unlikely to learn all of the Tier 2 words suggested to support strong reading development.

One potential method of addressing the need for greater efficiency of Tier 2 word instruction is to adjust instructional intensity based on word difficulty. For example, to use the Beck et al., (1987) three-tiered framework for selecting suitable vocabulary words would result in a set of words highly diverse in properties such as in length, meaning, part of speech, language of origin, spelling, number of different meanings, etc. For example, pounce, dazzling, and masterpiece are among the many Tier 2 vocabulary words Beck et al. (2013) propose as suitable for instruction in primary grades. What unifies these three vocabulary words is that they are unfamiliar to the learner, yet appear frequently in text and oral language and can be explained using concepts already familiar to the learner (Beck et al., 2013). Are these three words, then, of relatively equal difficulty level? The current study examines the difficulty level of Tier 2 words based on certain properties.

\section{Word Difficulty and Word Properties}

Word difficulty, or the level of difficulty in learning or remembering the meaning of a particular word, has long been a popular topic of research inquiry (Dolch, 1932). Word difficulty research offers a foundation on which to base understanding of vocabulary development and the evaluation of verbal skills in children (Breland, 1996; Tamayo, 1987). It has also been an area of particular interest within the context of adult foreign language learning (De Groot \& Keijzer, 2000; Laufer, 1990a). There is no general consensus, however, about what exact properties 
or combination of properties are sure to make certain words more difficult to learn than others for children who have low vocabulary skills.

Among a more general population, different word properties, sometimes referred to as features or characteristics, have been associated with word difficulty. For example, a word's frequency has been shown to be correlated with ease of learning and remembering (Lotto \& De Groot, 1998). Other word properties that influence word difficulty include a word's length and meaning, its part of speech, whether or not it is onomatopoetic or a compound word, its degree of abstractness in meaning, its cognate status, and others (Breland, 1996; De Groot \& Keijzer, 2000; Laufer, 1990b). Further, a study that investigated the impact of story content on word learning found that words that are fantasy-themed (e.g., throne, galloped) are easier for children to learn than those that are reality-themed (e.g., chimney, peaceful) (Weisberg et al., 2015).

What has not been explored thus far is the degree of difficulty among only Tier 2 words, specifically for at-risk children. Given that it is recommended that children entering school are to be directly taught Tier 2 words, the focus on this subset of words alone is necessary for beginning to understand which of these words at-risk children have difficulty learning, why that may be, how to best support their learning, and particularly, how word difficulty data can serve as an instructional tool.

A focus of this study is the relatedness of a Tier 2 word's concreteness to student vocabulary learning outcomes. Concreteness refers to the ability to perceive through visual, aural, gustative, olfactive, or tactile senses. De Groot and Keijzer (2000) found that among foreign-language learners, a vocabulary word's concreteness 
was positively correlated with ease of learning its meaning. This suggests that a word such as evolve, a relatively abstract word, is more difficult to learn than the word kiosk, a relatively more concrete word (Brysbaert, Warriner, and Kuperman, 2014).

It is suggested that concreteness is related to word difficulty because, for example, children learn nouns more readily than verbs due in part to their imageability, or degree to which a word gives rise to a mental image, of nouns (Maguire, Hirsh-Pasek, \& Golinkoff, 2006; McDonough et al., 2011). Concreteness is highly correlated with imageability (Paivio, Yuille, \& Madigan, 1968) and the concepts are often used interchangeably in literature on memory (Maguire et al., 2006). A benefit of studying concreteness rather than imageability, however, is that future research could draw on the results of the current study to investigate the effects of vocabulary instruction that incorporates perception through the five senses, on word learning difficulty in order to examine the degree to which it may improve learning outcomes.

Another word property explored in this study that relates to vocabulary word difficulty is that of a word's length, as measured in syllables (Laufer, 1990b). It is suggested that polysyllabic words are more difficult than monosyllabic words. Though exceptions exist, generally, syllable counting is a relatively quick and easy method of gauging word difficulty (Stahl \& Nagy, 2006). Research on how syllable counts impact word difficulty mainly focuses on their relation to word processing and reading abilities (Muncer, Knight, Adams, 2014). The current study appears to be the first effort to examine how a word's syllable count influences at-risk children's learning of Tier 2 words. 


\section{Vocabulary Instructional Practices}

At this time, evidence-based, direct vocabulary instruction offers a standardized, sometimes manualized, approach to teaching word meanings. Even with wide-ranging differences in properties across target words, current research recommends a uniform recipe of direct, explicit, and systematic vocabulary instruction featuring multiple components. Some of these components, or strategies, include providing pre-instruction of word prior to exposure through reading (NRP, 2000), student-friendly explanations of the words, repeated exposures, opportunities for students to interact with word meanings (Beck et al., 2013), examples and nonexamples (Stahl \& Nagy, 2006), and presenting words within meaningful contexts (Beck et al., 2013; Stahl \& Nagy, 2006). Though a standardized approach to instruction of vocabulary words might seem simpler than an approach informed by each word's properties at the outset, the latter has potential to be a more efficient method overall. There may be utility, therefore, in being able to identify the vocabulary words likely to be more difficult for children to learn than others in the event that providing a form of enriched instruction for those particular words or types of words upfront, ultimately benefits student learning. First, it is necessary to identify any properties that may contribute to the difficulty of at-risk children learning Tier 2 vocabulary words.

The current study explores results of a recent, large-scale early vocabulary intervention study by examining the relationship between gross properties of the target vocabulary words and at-risk students' learning outcomes over time. Such research inquiry serves as a way to better understand which types of vocabulary words, if any, 
at-risk children have difficulty learning. It is important to better understand the extent to which properties such as concreteness and word length relate to learning Tier 2 word meanings, so as to inform the educator's choices in word selection, word groupings, instructional strategy, and vocabulary assessment, for examples (Laufer, 1990). It would be necessary for further research to investigate the utility of providing educators with this practical knowledge about the vocabulary words being taught to a particularly vulnerable population of children.

\section{Vocabulary Assessment}

Measuring all of one's vocabulary knowledge would, in fact, require measuring one's "vocabularies." Researchers and practitioners distinguish between receptive and productive/expressive vocabularies, as well as subcategories of oral, reading, and sight vocabularies (NRP, 2000). Receptive, or recognition, vocabulary is the vocabulary that is understood when spoken to or presented in text. Productive, or expressive, vocabulary refers to the vocabulary used in writing or speaking. Receptive vocabulary is often larger than one's expressive vocabulary as individuals often recognize certain words, though they may not use them in writing or speech (NRP, 2000). Expressive vocabulary knowledge, however, is suggested to be a stronger predictor of later reading achievement than is receptive vocabulary knowledge (Snow, Burns, \& Griffin, 1998).

Despite the difficulty of precisely measuring an individual's complete vocabulary knowledge, receptive and expressive vocabulary assessments provide a good estimate. This can be done using standardized, norm-referenced measures or experimenter- or teacher-developed tests (NRP, 2000). A commonly used norm- 
referenced, standardized measure for assessing general receptive vocabulary knowledge is the Peabody Picture Vocabulary Test- Fourth Edition (PPVT-4) (Dunn \& Dunn, 2007). This measure is structured such that the examiner orally provides a vocabulary word and the respondent points to the corresponding picture of the four picture options on the page. A commonly used norm-referenced, standardized measure for assessing general expressive vocabulary knowledge is the Expressive Vocabulary Test-Second Edition (EVT-2) (Williams, 2006), in which a respondent orally produces one word that answers the examiner's question about a presented picture. Another method of assessing expressive vocabulary knowledge is one in which the respondent verbally produces a definition for a spoken or written vocabulary word, such as in the experimenter-developed expressive outcome measure used in the current study.

Standardized, norm-referenced vocabulary measures are useful for obtaining a general level of vocabulary knowledge, but are less useful for detecting change or growth as they may not feature the target vocabulary words taught in a given classroom (NRP, 2000). Experimenter- or teacher-developed instruments, rather, are more sensitive to vocabulary change when it is important to assess knowledge of certain words. The experimenter- or teacher-developed instruments can measure either expressive or receptive vocabulary.

Vocabulary assessment is complicated by the lack of consensus in the field about what it means to know the meaning of a word. If, for example, one can accurately identify a word measured receptively, but not expressively, does that individual truly know the word? Though it is agreed upon that word knowledge is not 
an all-or-nothing concept, there are a variety of descriptions about levels of word knowledge.

Beck et al., (2013) point out that knowledge about a word can range quantitatively, that is, a little to a lot of knowledge, as well as qualitatively. Dale (1963) recognized four stages of word knowledge: Stage 1) Never heard it before; Stage 2) Heard it, but don't know what it means; Stage 3) Recognizes it in context as having something to do with (blank); Stage 4) Knows it well. Beck et al. (1987) suggest that word knowledge falls along a continuum beginning with no knowledge; having a general sense of the word; having a narrow, context-bound knowledge; having knowledge but not enough to recall it; and finally, having rich, decontextualized knowledge with the ability to extend to metaphorical uses. Given the various levels to word knowledge, along with their advantages and disadvantages (instructional time invested versus utility of knowledge gained), educators should thus set breadth versus depth of word knowledge goals prior to instruction and assessment.

Degree of word knowledge relates to vocabulary assessment because assessments differ in terms of the degree of word knowledge that must be expressed in order to earn full "credit" for that word. For example, if an individual knows only the general sense of a word, he or she might earn only partial credit or even no credit for it on an expressive vocabulary measure, whereas for that same word, he or she might earn full credit on a receptive measure in which pictures are presented as options, a type of multiple choice format. The word emergency, for example, might be difficult to orally define for one who possesses only a general sense of the word, but in this case it might be easier to recognize when presented in picture form, such as an image 
of an ambulance. In this case, the respondent would earn partial or no credit on the expressive measure yet full credit on the receptive measure for the same target vocabulary word. As previously mentioned, when making decisions about which assessment to administer, the learning goals (i.e., breadth versus depth of word knowledge) must be considered (Beck et al., 2013).

Finally, the timing of vocabulary assessment is an important consideration and is suggested to have implications for the measurement of target word learning. Learning a new vocabulary word takes times, that is, it takes multiple exposures or experiences to achieve the rich, decontextualized knowledge of the word that Beck et al. (1987) suggest constitutes replete knowledge of that word (Nagy \& Scott, 2000). Though there is not an exact amount of time it takes to learn a word, Beck et al. (2013) propose that such encounters should extend beyond a mere week of instructional focus should the goal be for the word to be a part of the permanent vocabulary repertoire. The goal may not be quite as lofty as achieving this expert command of the word, but clearly, administering a vocabulary assessment prior to devoting adequate instructional time has the potential to produce misleading results.

Alternatively, vocabulary assessments could also be administered beyond when would be considered optimal timing. Based on what is theorized about memory decay (i.e., fading of knowledge over time) and memory interference (i.e., new information disrupts old information or vice versa) (Baddeley, 1997), it could be argued that assessment should occur immediately to avoid "loss" of learned word knowledge. There is a dearth of literature surrounding when exactly vocabulary assessment in the classroom should occur following instruction, however, awareness 
of these issues is important. A secondary research question of the current study relates to how word properties influence the target vocabulary word learning outcomes after controlling for the length of time between vocabulary instruction and vocabulary assessment.

\section{Current State of Vocabulary Instruction}

Direct vocabulary instruction in the classroom is a relative newcomer in the field of education, especially when compared to more traditional subjects such as reading, writing, and arithmetic. Its benefits for emerging readers have garnered the attention of researchers and educators throughout the last several decades (Chall, Jacobs, \& Baldwin, 1990; NICHD, 2000; Scarborough, 2001).

With a plethora of research evidence justifying its place in early reading curriculum, direct vocabulary instruction continues to make its way into primary grade (and beyond) classrooms. Still, studies suggest that not enough is being done to promote vocabulary growth in primary education (Beck et al., 2013; Biemiller, 2012; Cuticelli et al., 2015; Stahl \& Nagy, 2006; Wanzek, 2016). For example, Wright and Neuman (2014) studied the typical vocabulary instructional practices in 55 Kindergarten classrooms across 46 socio-economically-diverse schools and results revealed that the vocabulary instruction consisted only of brief word explanations during "teachable moments." This type of practice is at odds with what evidence suggests about the need for multi-faceted, explicit and systematic vocabulary instruction that includes systematic word selection, opportunities to practice using the word, and repeated exposures (NRP, 2000). Moreover, in the more economically advantaged schools of the study, teachers were found to provide a greater number of 
instances of these "teachable moments" and the words taught were more challenging than in the less advantaged schools (Wright \& Neuman, 2014). The discovery of insufficient vocabulary instructional practices in this study is quite alarming, and what may be more worrisome is the disparity in vocabulary instruction between low SES schools and their more advantaged counterparts.

Like other academic subjects, direct vocabulary instruction demands educational time and resources, both of which educators undoubtedly covet and aim to use efficiently. While research is needed to inform practice, practice must also inform research. As such, it should be the aim of vocabulary researchers to continue to support early vocabulary development by exploring ways to improve efficiency of practices and make them as accessible and user-friendly as possible.

\section{Research Questions}

The current study examines the relationship of word properties (i.e., concreteness and syllable count) and target vocabulary word learning outcomes as measured by experimenter-developed expressive and receptive vocabulary outcome measures following implementation of multi-tiered vocabulary instruction (Beck \& McKeown, 2004; Coyne, McCoach, Loftus-Rattan, Baker, \& Santoro, 2011) in Kindergarten. The primary and secondary research questions are addressed in the current study:

\section{Primary Research Questions}

1. Concreteness. What is the relationship between target word degree of concreteness and short-term and long-term expressive and receptive target word learning outcomes? 
1a. Short-Term. To what degree does target word concreteness predict target word knowledge (expressive and receptive) from preintervention (beginning of kindergarten) to post-intervention (end of Kindergarten) (i.e., short-term)?

1b. Long-Term. To what degree does target word concreteness predict target word knowledge (expressive and receptive) from preintervention (beginning of Kindergarten) to post-intervention (end of Grade 1) (i.e., long-term)?

1c. Long-Term. To what degree does target word concreteness predict target word knowledge (expressive and receptive) from preintervention (beginning of Kindergarten) to post-intervention (mid-year Grade 2) (i.e., long-term)?

2. Syllable Count. What is the relationship between target word syllable count and short-term and long-term expressive and receptive target vocabulary word learning outcomes?

2a. Short-Term. To what degree does target word syllable count predict target word knowledge (expressive and receptive) from preintervention (beginning of kindergarten) to post-intervention (end of Kindergarten) (i.e., short-term)?

2b. Long-Term. To what degree does target word syllable count predict target word knowledge (expressive and receptive) from preintervention (beginning of Kindergarten) to post-intervention (end of Grade 1) (i.e., long-term)? 
2c. Long-Term. To what degree does target word syllable count predict target word knowledge (expressive and receptive) from preintervention (beginning of Kindergarten) to post-intervention (mid-year Grade 2) (i.e., long-term)?

\section{Secondary Research Questions}

3. Influence of Week in which Target Words were Introduced/Taught. The target vocabulary words varied by time, in weeks, between initial instruction and assessment. For example, the length of time between instruction and assessment of target vocabulary words taught in Week 1 of the intervention is greater than the length of time between instruction and assessment of target vocabulary words taught in Week 20. What is the relationship between word concreteness and syllable count on target vocabulary word learning (expressive and receptive) when controlling for the week number of the intervention in which the target vocabulary words were taught/introduced?

3a. To what degree does word concreteness predict target word knowledge (expressive and receptive) when controlling for the week number of the intervention in which the target vocabulary words were taught/introduced?

3b. To what degree does word syllable count predict target word knowledge (expressive and receptive) when controlling for the week number of the intervention in which the target vocabulary words were taught/introduced? 


\section{CHAPTER 3}

\section{METHODOLOGY}

\section{Design}

The current study, a secondary data analysis, was conducted in the context of a longitudinal vocabulary intervention study entitled, Early Vocabulary Intervention (EVI) (Coyne et al., 2011). Project EVI was funded by the U.S. Department of Education Institute for Education Sciences and led by prominent researchers in the Northeastern and Northwestern US who collaborated on the project for approximately five years.

Project EVI. In Project EVI, kindergarten teachers were trained to implement the empirically-supported Elements of Reading: Vocabulary (EOR-V) curriculum (Beck \& McKeown, 2004), which they delivered in whole-classroom format (Tier 1) over the course of the academic year. The teachers taught five new target words each week through daily lessons activities from the EOR-V (Beck \& McKeown, 2004) curriculum, a kindergarten through fifth-grade curriculum that has been shown to boost vocabulary skills and reading achievement in randomized controlled trials (Apthorp, 2006).

The primary purpose of Project EVI was to rigorously test the effects of an experimenter-developed Tier 2 vocabulary intervention (here, the term Tier 2 refers to a targeted level of intervention intensity, not a subset of words) delivered to at-risk students. As such, a select group of at-risk students received an additional 20-30 minutes of small-group vocabulary instruction each week (Tier 2 intervention) 
delivered by trained school-based staff. Project EVI featured a strong experimental design, with random assignment of at-risk students to control or treatment groups.

More specifically, of the total number of Kindergarten students screened for participation in the EVI study, 2353 (44\% female) students were included as part of the study. Inclusionary criteria was based on the results of a common universal screening tool, the Peabody Picture Vocabulary Test (PPVT-4) (Dunn \& Dunn, 2007), a norm-referenced measure of an individual's breadth of general receptive vocabulary knowledge year (Hoffman, Teale, \& Paciga, 2014). Upon administration at the beginning of the school, PPVT-4 scores were derived using total items correct and the respondent's chronological age. The PPVT-4 has a reported test-retest reliability of .92 (Dunn \& Dunn, 2007).

Students who scored between the $5^{\text {th }}$ and $30^{\text {th }}$ percentile on the PPVT- 4 were identified as being at-risk for later reading difficulties and, therefore, were eligible for assignment to either the treatment or control group. These PPVT cut-off scores have been used in a number of studies as a method for determining level of risk at the time of screening (Cuticelli et al., 2015; Loftus \& McCoyne, 2013; Pullen, Tuckwiller, Konold, Maynard, \& Coyne, 2010).

The at-risk students, who scored between the $5^{\text {th }}$ and $30^{\text {th }}$ percentiles on the PPVT-4 and were randomly assigned to either the control group ( $\mathrm{N}=780 ; 42 \%$ female) or the treatment group ( $\mathrm{N}=853 ; 48.5 \%$ female), all demonstrated a need for more intensive vocabulary support, but due to the nature of a quasi-experimental design, only half (i.e., the treatment group) received it. The control group received Tier 1, whole-classroom vocabulary instruction only. The treatment group received Tier 1, 
whole-classroom vocabulary instruction and Tier 2, small-group vocabulary intervention, which provided supplemental instruction on a portion of the vocabulary words taught at the Tier 1 level. The at-risk participants included in the treatment group are the participants and focus of the current study $(\mathrm{N}=853)$. See Table 2 for demographic data and Table 3 for clustering data of participants within each study at the individual, classroom, school, and regional levels.

All groups received daily Tier 1 classroom instruction with the Elements of Reading: Vocabulary (EOR-V) (Beck \& McKeown, 2004) curriculum. This Tier 1 instruction comprised pre-instructions, read-alouds and word definitions, various follow-up activities, review, and assessment (See Figure 1). In the treatment group only, students received an additional 20-30 minutes of Tier 2 intervention 4 days per week, which focused on three of the five Tier 1 target words delivered by trained, school-based personnel (e.g., paraeducators, special educators, reading specialists). For example, during Lesson (i.e., week) 1, all students were introduced to and explicitly taught five words comforting, glimmer, lively, fleet, and expression within Tier 1 over the course of five days per week. 
Table 2

Participant Demographic Characteristics

\begin{tabular}{lllll}
\hline & \multicolumn{2}{l}{ Project EVI N=2351 } & $\begin{array}{l}\text { Current Study (Tx Group) } \\
\text { N=853 }\end{array}$ \\
\hline Characteristic & Number & Percent & Number & Percent \\
Sex & & & & \\
Female & 1042 & 44 & 348 & 48.5 \\
Male & 1132 & 48 & 414 & 40.8 \\
Missing & 177 & 8 & 91 & 10.7 \\
& & & & \\
Race/Ethnicity & & & & 38.2 \\
Hispanic & 836 & 35.5 & 326 & 19.9 \\
Black & 462 & 19.6 & 170 & 17.6 \\
White & 559 & 23.8 & 150 & .4 \\
Amer. Indian/Alaskan & 12 & .5 & 3 & 3.9 \\
Asian/Pacific Islander & 81 & 3.4 & 33 & 7.5 \\
Two or More Races & 182 & 7.7 & 64 & .8 \\
Other race not listed & 16 & .6 & 7 & 11.7 \\
Missing & 205 & 8.7 & 100 & \\
& & & & 51.3 \\
ELL Status & & 37 & 324 & 38 \\
ELL & 792 & 58 & 438 & 10.7 \\
Not ELL & 1373 & .8 & 91 & \\
Missing & 188 & & & \\
\hline
\end{tabular}

For the treatment group only, three of those five words, comforting, glimmer, and fleet, were then reintroduced and expanded on in a small group later in the day (Tier 2 intervention) four days per week. Selection criteria for the subset of three of the five Tier 1 target words that became the focus of the Tier 2 intervention related to their sequencing in the EOR curriculum (Beck \& McKeown, 2004). The first three target vocabulary words of each EOR weekly lesson received the extra "dosage" of instruction in the Tier 2 small-group intervention (See Appendix A). 
Table 3

\section{Participant Clustering}

\begin{tabular}{cll}
\hline & Project EVI & Current Study (Tx Group) \\
\hline Cluster & Number & Number \\
Northeast US & & \\
Schools & 29 & 28 \\
Classrooms & 184 & 159 \\
Students & 1430 & 501 \\
& & \\
Northwest US & & \\
Schools & 20 & 20 \\
Classrooms & 100 & 91 \\
Students & 923 & 321 \\
& & 853 \\
Total Students & 2351 & \\
\hline
\end{tabular}

The Tier 2 intervention model comprised reintroduction of words learned in whole-classroom instruction, various activities involving practicing using the words, and review (See Figure 2). Though the Tier 1 instruction and Tier 2 intervention were implemented for 24 weeks, post-testing was conducted once Lesson 20 was completed and, therefore, any words taught beyond Lesson 20 were not part of testing. See Appendix A for weekly instructional sequencing for Tier 1 instruction and Tier 2 intervention for Lessons 1-20.

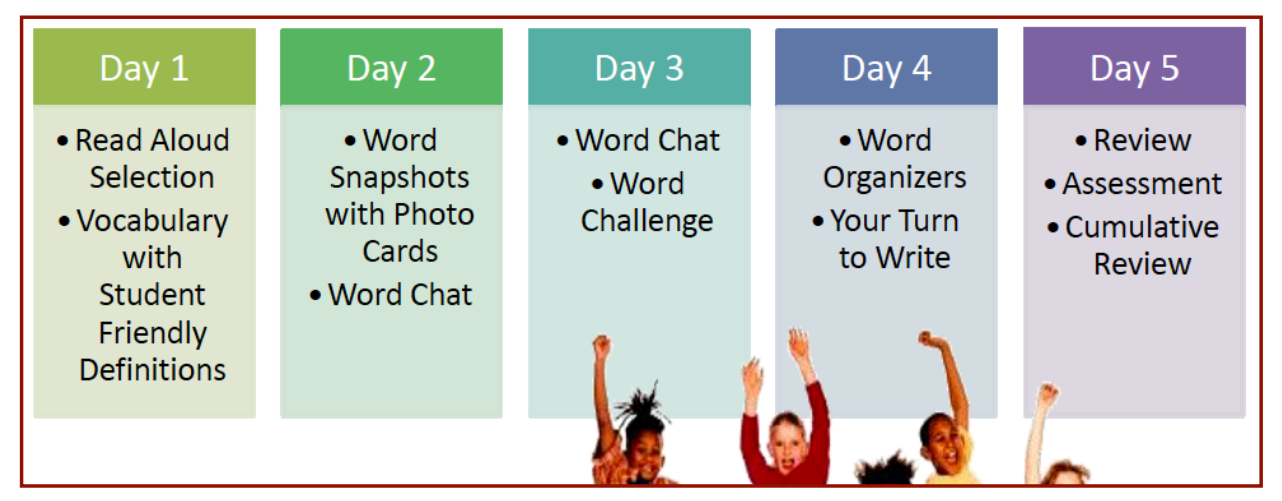

Figure 1. Weekly Tier 1 Instruction (whole-class) Overview. 


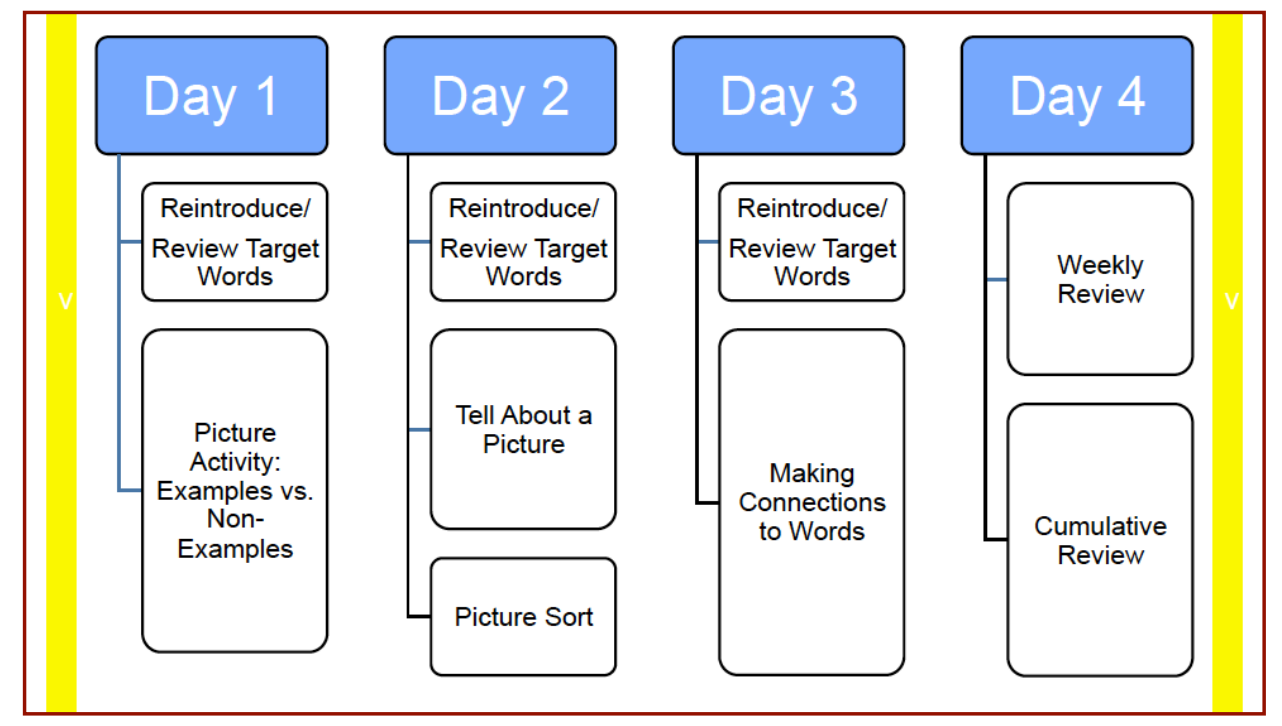

Figure 2. Weekly Tier 2 Intervention (small-group) Overview.

Trained data collectors (graduate students and other individuals with experience in a related field) for Project EVI conducted in-school pre- and postintervention assessment relating to target vocabulary word knowledge and other early language and literacy skills. Follow-up assessment was also conducted in the beginning and end of Grade 1 and mid-year of Grade 2 in order to examine any longterm effects of the Tier 2 Kindergarten vocabulary intervention.

\section{Measurement}

\section{Vocabulary Outcome Measures}

Project EVI administered numerous language and literacy measures at pre- and post-intervention phases. Those relevant to the current study measured knowledge of the target vocabulary words (i.e., not general vocabulary knowledge). Target vocabulary knowledge was assessed at pre- and post-intervention phases (beginning and end of Kindergarten, respectively) using two experimenter-developed vocabulary 
measures, Expressive Target Vocabulary Word and Receptive Target Vocabulary Word (See Appendix A). As previously mentioned, follow-up assessment was also conducted using these measures at the beginning and end of the first grade, and at mid-year during second grade. These measures were developed using the target vocabulary words featured in the Tier 1 Elements of Reading (EOR-V) (Beck \& McKeown, 2004) curriculum, all of which were also featured in the experimental Tier 2 intervention. According to the National Reading Panel (2000), researcher-developed measures such as these are well suited for assessing vocabulary growth due to their sensitivity to knowledge of targeted words, unlike norm-referenced standardized measures.

Expressive Target Word Vocabulary Measure. The expressive measure, administered individually, assesses expressive knowledge of target word definitions by asking the respondent to orally provide the definition of 26 target words (a sampling of the 120 vocabulary words taught throughout the 24-week Tier 1 instruction and Tier 2 intervention). Scored using a rubric, responses for each item on the expressive measure are worth 0,1 , or 2 points, for incorrect, partially correct, or correct responses, respectively. The total score reflects the sum of individual item scores on the 26 total expressive items. The expressive measure was scored by multiple trained raters who first achieved inter-rater reliability calculated using the percent agreement method.

Receptive Target Word Vocabulary Measure. The receptive measure, also administered individually, assesses receptive knowledge of 16 target words (a sampling of the 120 vocabulary words taught throughout the 24-week Tier 1 
instruction and Tier 2 intervention). The respondent chooses one picture out of four options that correctly matches the word provided orally by the examiner. Each item response is scored as incorrect or correct, 0 or 1 points, respectively. The total score reflects the sum of individual item scores on the 16 total receptive items.

Given that the expressive and receptive measures comprise a different number of total items, they do not account for the words equally. The expressive measure comprises 26 items and therefore assesses 26 target vocabulary words, and the receptive comprises 16 items and therefore assesses 16 target vocabulary words. The 16 receptive target vocabulary items all overlap with the 26 expressive target vocabulary items, with an additional 10 target vocabulary words on the expressive measure that were not measured receptively. The target vocabulary words that the EVI researchers included on the expressive measure but not the receptive measure appear in bold in Appendix B.

\section{Word Properties}

For the current study, word properties constitute word concreteness and a word's number of syllables, for which values were taken from existing research databases.

Concreteness. Word concreteness values were taken from a reference list developed by Brysbaert et al. (2014), which contains 39,954 English words systematically rated by native English-speaking adults on a 5-point Likert scale from highly abstract (e.g., inadvertently) to highly concrete (e.g., eggplant). Below, the exact instructional statement is included in order to specify the rating procedure in the Bysbaert et al. (2014) study and to explicate what is meant by the term concreteness as it pertains to 
the current study. Prior to rating, the participating raters received the following information:

Some words refer to things or actions in reality, which you can experience directly through one of the five senses. We call these words concrete words. Other words refer to meanings that cannot be experienced directly but which we know because the meanings can be defined by other words. These are abstract words. Still other words fall in-between the two extremes, because we can experience them to some extent and in addition we rely on language to understand them. We want you to indicate how concrete the meaning of each word is for you by using a 5-point rating scale going from abstract to concrete. A concrete word comes with a higher rating and refers to something that exists in reality; you can have immediate experience of it through your senses (smelling, tasting, touching, hearing, seeing) and the actions you do. The easiest way to explain a word is by pointing to it or by demonstrating it (e.g. To explain 'sweet' you could have someone eat sugar; To explain 'jump' you could simply jump up and down or show people a movie clip about someone jumping up and down; To explain 'couch', you could point to a couch or show a picture of a couch).

An abstract word comes with a lower rating and refers to something you cannot experience directly through your senses or actions. Its meaning depends on language. The easiest way to explain it is by using other words (e.g. There is no simple way to demonstrate 'justice'; but we can explain the meaning of the word by using other words that capture parts of its meaning). 
Because we are collecting values for all the words in a dictionary (over 60 thousand in total), you will see that there are various types of words, even single letters. Always think of how concrete (experience based) the meaning of the word is to you. In all likelihood, you will encounter several words you do not know well enough to give a useful rating. This is informative to us too, as in our research we only want to use words known to people. We may also include one or two fake words which cannot be known by you. Please indicate when you don't know a word by using the letter N (or n) (Brysbaert et al., 2014, p. 9-10).

For the current study, all 26 target vocabulary words included on the target word outcome measure were assigned a concreteness value based on the reported concreteness value target word as it appeared in the reference list (Bysbaert et al. (2014). One target word, however, did not appear on the reference list exactly as it was taught in the interventions. This target vocabulary word, startle, was not in the Brysbaert et al. (2014) reference list. A word that does appear in it, however, is startled. Despite this difference in word tense, the concreteness value for startled was substituted for that of startle in the current study due to their closeness in meaning, and the likelihood that they would share similar concreteness values if startle had been reported in the reference list.

Syllable Count. The number of syllables per target vocabulary word was derived from The English Lexicon Project (ELP) (Balota et al., 2007), a database that provides access to the lexical characteristics (i.e., characteristics that contribute to the visual/ 
auditory processing of single words) of over 40,000 English words. The ELP was developed in an effort to extend lexical processing research from featuring only monosyllabic words to also include multi-syllabic words. Multi-syllabic words are believed to differ from monosyllabic words in stress patterning, morphological structure, and length effects and, therefore, were taken into consideration in the development of the database. Of the total number of words $(\mathrm{N}=40,481)$ examined in the ELP, the average number of syllables per word was 2.54 with a standard deviation of 1.10 (Balota, et al., 2007).

\section{Instructional Sequence}

Consistent with most early vocabulary programming, the target vocabulary words were introduced/taught over the course of the school year and therefore, at different points in time. As part of the small-group treatment intervention curriculum, three words (taken from the concurrent Tier 1 instruction) were emphasized each week over 24 weeks.

The two intervention outcome measures designed to assess outcome learning, however, were administered at the end of the 24-week intervention, thereby resulting in a gap of time between the instruction and assessment of words that is different for words taught early on in the school year as compared with those taught later. In the presented example, the assessment at the end of the 24-week intervention requires children to recall the words taught 24 weeks prior as well as words taught only 4 weeks prior. For example, during Week 1, students were taught the target words comforting, glimmer, lively, fleet, and expression. Later in the school year, during Week 20, for instance, students were taught the target words survey, mammoth, 
memorable, beacon, and labor. The target words taught during Week 20 may be more easily recalled due to a recency effect, the likelihood of remembering information due to its serial end position. Alternatively, recall of target words taught in Week 1 could be advantaged due to a primacy effect, the likelihood of remembering information due to its serial beginning position (Murdock, 1962).

Given that outcome assessment of all the vocabulary words was not administered in equal intervals following instruction, the effect of the week number of the intervention on target vocabulary word learning was examined as secondary research questions in an effort to control for the differing gap in time (measured in weeks) between target word instruction and assessment. Additionally, this inquiry offers practical implications for the timing of vocabulary assessment within the contexts of classroom and school-based research assessments.

\section{Analyses}

The research questions for the current study call for the evaluation of change in two dependent variables, expressive and receptive vocabulary word knowledge outcomes, over time, which involves analysis of longitudinal data of the repeated measures administered to the same student participants at different points in time (i.e., Kindergarten, Grade 1, and Grade 2). The primary research questions focus on the evaluation of the group-level effects of the two independent variables that, for this current study, constitute features of word difficulty (i.e., concreteness and syllable count). The secondary research question involves examination of the influence of the week number of the intervention in which the target vocabulary was introduced/taught (which was coded for by word, using the week number the word was 
introduced/taught as an indicator of time). Clustering by site controls for the influence of within-site heterogeneity due to inherent site differences on the estimates and tests of statistical inference.

Longitudinal data involving repeated measures tends to be correlated within subjects over time. As such, these data require that the within-subject heterogeneity be appropriately modeled to prevent violation of the statistical independence assumption of the general linear model. To ensure that the statistical estimates of group-level effects and group-level variation of primary interest to this study are unbiased, the statistical analysis employed was linear mixed-effect regression (LMER), which can accurately model for the within-subject heterogeneity (i.e., statistical dependency) in the data that is due to repeated measures, and provide unbiased estimates of the grouplevel effects. Within-subject variation must be accounted for in longitudinal analyses to avoid biased estimates of the fixed effects and their standard errors. The LMER model estimates two kinds of variance components, which are described as grouplevel (or fixed-effect) variation and within-subject individual level (or random-effect) variation. For the current study, the within-subject variation was not of interest to the current research, but instead constitutes nuisance variation that is controlled for to obtain accurate results.

For example, an LMER model will have fixed-effects terms to estimate the group-level intercept, $\beta_{0}$, and one or more fixed-effect slope terms $\beta_{1,} \beta_{2, \ldots} \beta_{\mathrm{n}}$, that provide(s) estimates of group-level change associated with each independent variable. In addition, the LMER model also provides random-effect variance components that estimate the within-individual variation in the dependent (i.e., outcome) measures over 
time, using terms that represent individual variation in initial status, $\beta_{0 i}$, and variation in the shape of change over time $\left(\beta_{1 i}, \beta_{2 i}\right.$, etc.). When the random-effect terms, which measure the discrepancy between an individual's intercept $\left(b_{0 i}\right)$ and the group intercept $\left(\beta_{0}\right)$, and an individual's slope $\left(b_{1 i}\right)$ and the group slope $\left(\beta_{1}\right)$, are correctly specified, the estimates of the estimate and variance of the fixed effects are unbiased.

In the current study, the standard form of a linear mixed-effects regression model (LMER) equation is expressed as:

$$
\begin{aligned}
y_{i j}=\beta_{0}(1)+\beta_{1}\left(t_{j}\right) & +\beta_{2}(\text { Concreteness })+\beta_{3}(\text { Syllable count })+\beta_{4}\left(t_{j}\right) *(\text { Concreteness }) \\
& +\beta_{5}\left(t_{j}\right) *(\text { Syllable count })+b_{0 i}+b_{1 i}+\varepsilon_{i j}
\end{aligned}
$$

Where:

- $y_{i j}$ is the value of the dependent variable for the $i$ th individual

$$
(i=1, \ldots, N) \text { at time } j
$$

- $\beta_{0}$ is the fixed intercept representing the model estimate of the group value of the dependent variable

- $\beta_{1}\left(\mathrm{t}_{j}\right)$ is the fixed slope at time $j$, representing the model estimate of change from baseline $\left(\mathrm{t}_{0}\right)$ of the group mean of the dependent variable at time ${ }_{j}$

- $\quad \beta_{2}$ (Concreteness) is the fixed slope of word concreteness representing the model estimate of concreteness at baseline, $\left(\mathrm{t}_{0}\right)$

- $\quad \beta_{3}$ (syllables) is the fixed slope of syllable count, representing the model estimate of syllable count at baseline, $\left(\mathrm{t}_{0}\right)$

- $\quad \beta_{4}\left(\mathrm{t}_{\mathrm{j}}\right) *($ Concreteness $)$ is the fixed effect of word concreteness at time $j$, representing the change from baseline $\left(\mathrm{t}_{0}\right)$ due to concreteness 
- $\quad \beta_{5}\left(\mathrm{t}_{\mathrm{j}}\right)^{*}$ (syllables) is the fixed effect of number of syllable count at time $j$, representing the change from baseline, $\left(\mathrm{t}_{0}\right)$, due to number of word syllables

- $b_{0 i}$ is the random intercept effect, representing the initial status of individual variation from the fixed group level intercept $\left(\beta_{0}\right)$

- $b_{1 i}$ is the random slope representing individual variation from the linear fixed group level slope $b_{1}$

- $\varepsilon_{i j}$ is the residual error for each $i$ th individual at time $j$

All models contain residual error $\left(\varepsilon_{j i}\right)$, which is assumed to be normally and independently distributed with a mean of 0 and variance of $\sigma^{2}$, expressed as $\mathrm{N} \sim\left(0, \sigma^{2}\right)$. Also, when included in the model, each random effect (i.e., $b_{0 i}, b_{1 i}, \ldots, b_{4 i}$ ) is also assumed to be $\mathrm{N} \sim\left(0, \sigma^{2}\right)$.

\section{Procedure}

The Project EVI team and the University of Rhode Island Institutional Review Board (IRB) approved the use of the EVI data for the purposes of the current study. Following electronic receipt of EVI data, which has maintained password protection, data management was performed using SPSS version 22. Data management involved isolating the treatment group data and relevant variables, followed by creating syntax for independent variables, preparing the structure of the dataset for LMER modeling, and creating a time variable for the purpose of controlling for the influence of the instructional sequencing. Descriptive and inferential statistics were then performed using SAS version 9.4 to examine the following research hypotheses:

1. Concreteness. Target word concreteness value will significantly predict short-term and long-term expressive and receptive target vocabulary word 
learning outcomes such that the degree of concreteness will correlate with outcome scores.

2. Syllable Count. Target word syllable count will significantly predict shortterm and long-term expressive and receptive target vocabulary word learning outcomes such that the syllable count will negatively correlate with the outcome scores.

3. Influence of Instructional Sequence. The instructional sequencing (i.e., the week of the intervention in which words were introduced/taught) of the target vocabulary words will help explain the influence of concreteness and syllable count on short- and long-term expressive and receptive target word learning outcomes. 


\section{CHAPTER 4}

\section{RESULTS}

Following data management in SPSS version 22 statistical software, the data was analyzed with SAS version 9.4 statistical software. In this LMER model (SAS Proc Mixed), two word properties, concreteness and syllable count, were used as predictors for expressive and receptive vocabulary outcomes at baseline (beginning of kindergarten) and follow-up (end of kindergarten, end of $1^{\text {st }}$ grade, and mid-year $2^{\text {nd }}$ grade) with fixed effects of time, adjusted group means, concreteness, and syllable count, the interactions between time and concreteness, between time and syllable count, and between time and group means.

For the secondary research question that considers the impact of the week in which the target vocabulary word was introduced/taught (i.e., instructional sequencing) on the influence of concreteness and syllable count on learning outcomes, the same approach was taken as with the primary analyses. See Appendix A for the sequencing of target vocabulary word for each week of the EVI intervention.

Regarding missing data, LMER models feature the Missing at Random (MAR) assumption, which automatically corrects for the correlation of all model variables with missing data for the dependent variable (i.e., covariate dependent missingness). Because of an inconsistency in Project EVI data collection procedures, in which Cohort 1 of participants $(\mathrm{N}=181)$ was not administered the Target Receptive 
Vocabulary Outcome Measure at time point 1, the baseline scores for this cohort were considered as missing data.

The linear mixed model found that participants' $(\mathrm{N}=853)$ expressive and receptive outcome scores significantly improved over time $(p<.001)$, that is, from time point 1 (i.e., baseline) through time point 4 (i.e., mid-year grade 2). Comparing this finding to that of the control group was an aim of Project EVI for demonstrating the effectiveness of the intervention. This was not, however, an aim of the current study. For both expressive and receptive outcome measures, there were significant effects at the individual level, classroom level, and school level.

The concreteness-time interaction was not statistically significant for receptive outcome measures $(p=.3)$ but, it was statistically significant for the expressive outcome measure at time point 2 (i.e., end of Kindergarten) $(p<.001)$. See Figure 3 for graphic depiction of the influence of concreteness on expressive and receptive target vocabulary word outcome scores.

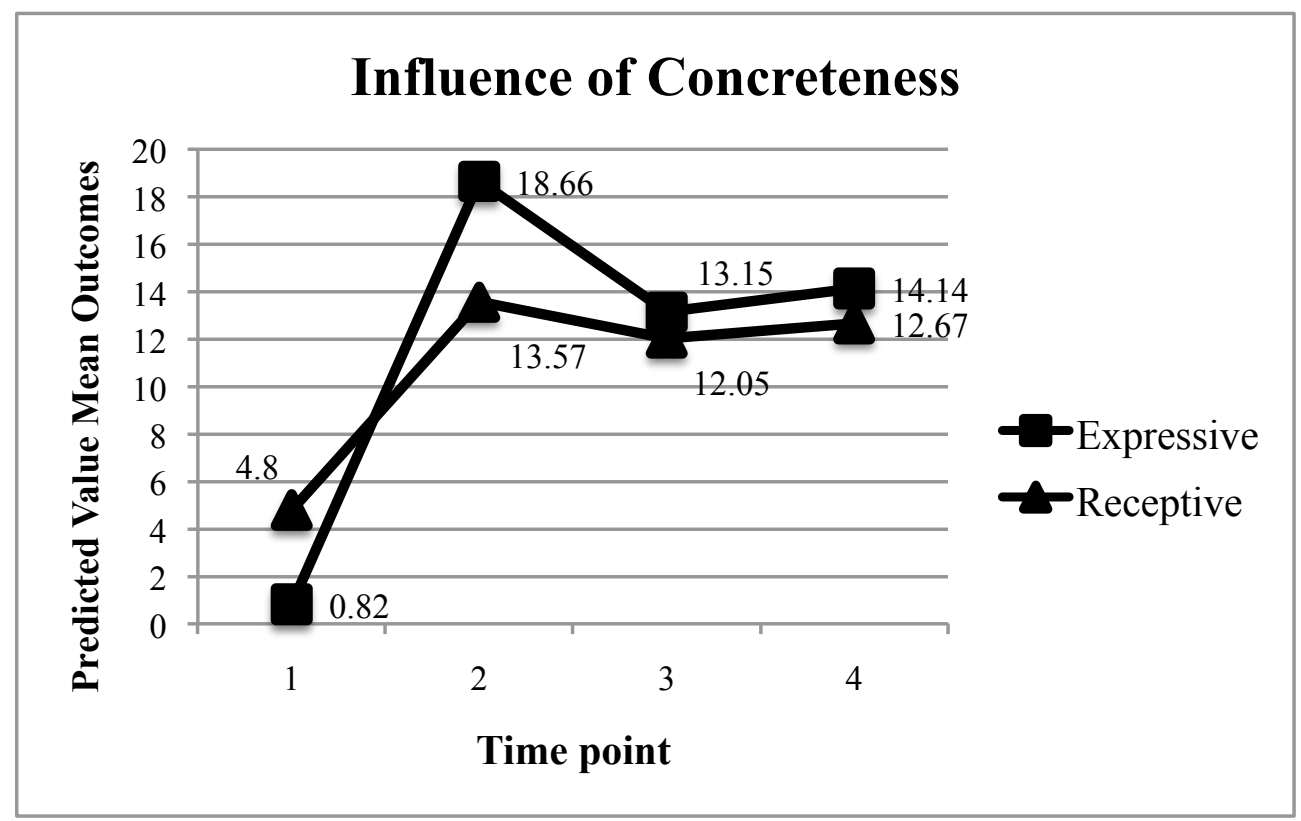


Figure 3. Group estimates for the influence of target word concreteness on expressive (square) and receptive (triangle) target vocabulary word outcomes over time (i.e., beginning of kindergarten, end of kindergarten, end of $1^{\text {st }}$ grade, and mid-year $2^{\text {nd }}$ grade).

The syllable count-time interaction for the receptive outcome measure was statistically significant $(p<.001)$ at all time points, with $t$-values indicating that the relationship is negatively correlated at each of these time points. The syllable counttime interaction for the expressive outcome measure was statistically significant $(p<$ .001 ) at time point 2 (end of Kindergarten). See Figure 4 for graphic depiction of the influence of syllable count on expressive and receptive target vocabulary word outcome scores.

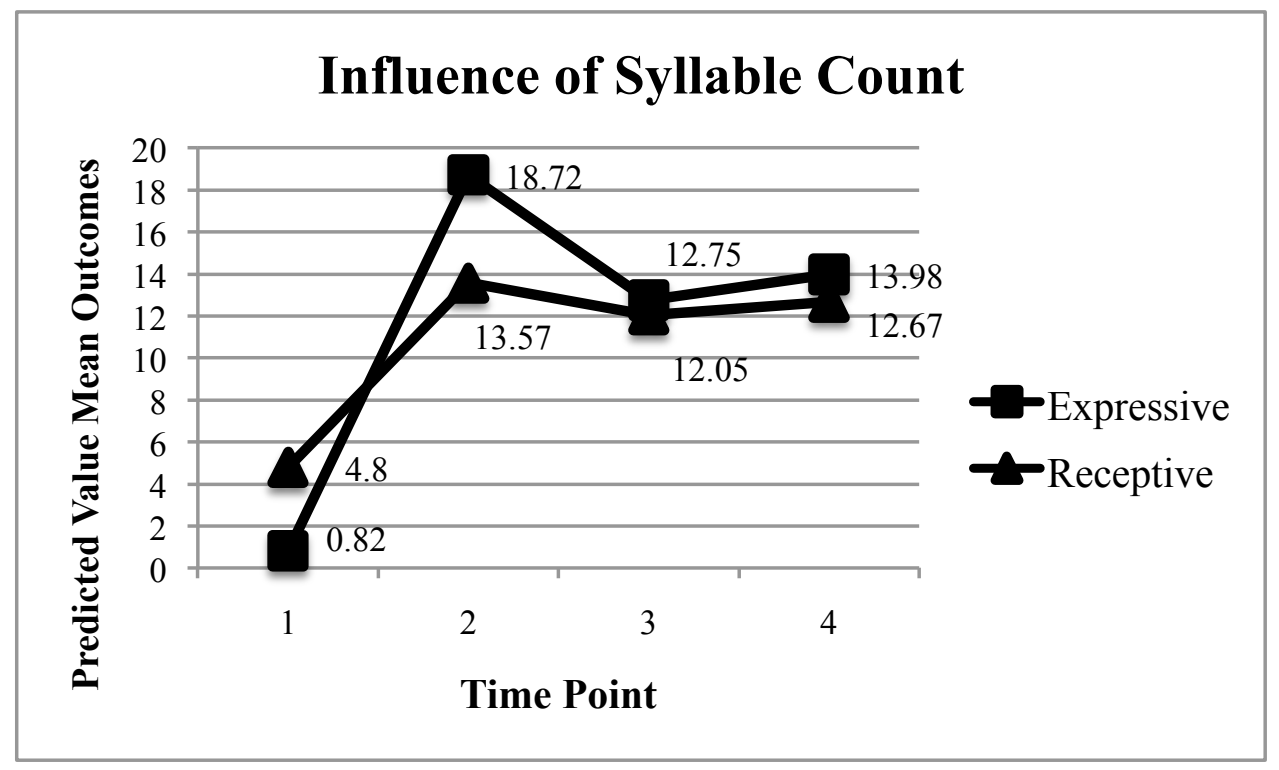

Figure 4. Group estimates for the influence of target word syllable count on expressive (square) and receptive (triangle) target vocabulary word outcomes over 
time (i.e., beginning of kindergarten, end of kindergarten, end of $1^{\text {st }}$ grade, and midyear $2^{\text {nd }}$ grade).

In examining the influence of the week number of the intervention in which the target word was introduced/taught on learning outcomes, the week of instruction-time interaction for the receptive outcome measure was statistically significant at time points 2 and 3 ( $p=.01$ for each). Time point 2 , however, has a negative $t$-value indicating an inverse correlation between the week number in which the words were introduced/taught and outcome scores. Also, the week of instruction-time interaction for the expressive outcome was statistically significant at time points 3 and 4 ( $p=.02$ for each). Figure 5 depicts the influence of the week of the intervention in which the target word was introduced/taught on expressive and receptive target vocabulary word outcome scores.

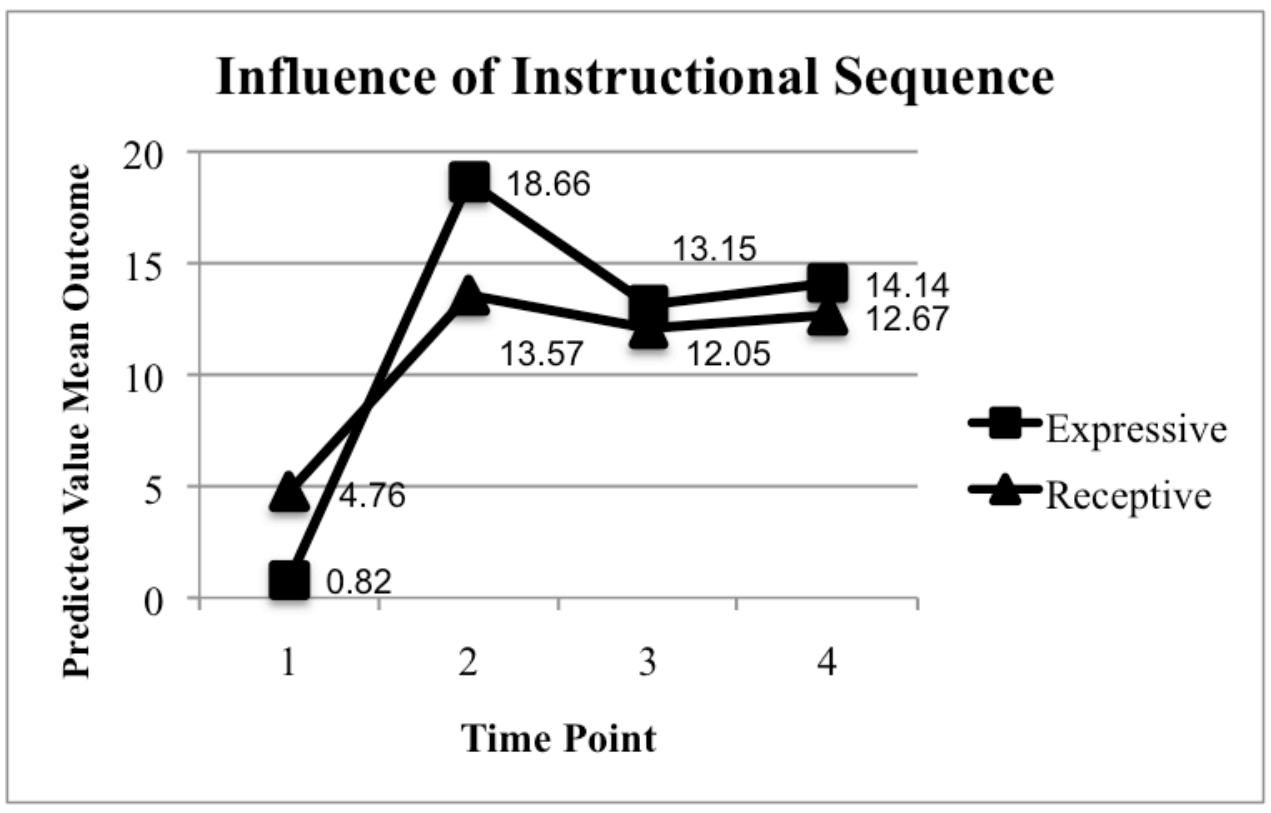

Figure 5. Group estimates for the influence of the week of the intervention in which the target word was introduced/taught on expressive (square) and receptive (triangle) 
target vocabulary word outcomes over time (i.e., beginning of kindergarten, end of kindergarten, end of $1^{\text {st }}$ grade, and mid-year $2^{\text {nd }}$ grade).

When controlling for the week number of the intervention in which the target word was introduced/taught, the influence of word concreteness on expressive target word vocabulary outcome scores was significant at time points $2(P<.001)$ and $3(P=$ $.01)$. When the week number of the intervention in which the target word was introduced/taught was controlled for, the influence of word concreteness on receptive target word vocabulary outcome scores, however, did not have a significant effect at any time point. Table 4 and Table 6 show the results of the final model (i.e., the threelevel mixed model) for the effect of concreteness on Expressive and Receptive vocabulary outcomes, respectively. Table 5 and Table 7 present the covariance parameter estimates for the effect of concreteness on expressive and Receptive vocabulary outcomes, respectively, which included adjustments for individuals nested within classroom, and those classrooms nested within schools. See Figure 6 for graphic depiction of these results.

Table 4

Regression Table: Concreteness on Expressive Outcomes

Solution for Fixed Effects

\begin{tabular}{llrrrrr}
\hline Effect & Time & Estimate & $\begin{array}{l}\text { Standard } \\
\text { Error }\end{array}$ & & t Value & Pr $>|t|$ \\
\hline Intercept & & 0.7056 & 0.5461 & 47 & 1.29 & 0.2026 \\
Time & 0T2 & 10.0586 & 1.3603 & 1279 & 7.39 & $<.0001$ \\
Time & 0T3 & 9.3339 & 2.1419 & 1279 & 4.36 & $<.0001$ \\
Time & 0T4 & 9.6339 & 3.9158 & 1279 & 2.46 & 0.0140 \\
Time & BL & 0 & &. &. & \\
concreteE & & 0.8428 & 0.3765 & 1279 & 2.24 & 0.0254 \\
concrete*Time & 0T2 & 2.8386 & 0.6832 & 1279 & 4.15 & $<.0001$ \\
concrete*Time & 0T3 & 1.9211 & 0.9331 & 1279 & 2.06 & 0.0397 \\
concrete*Time & 0T4 & 2.4044 & 1.4407 & 1279 & 1.67 & 0.0954
\end{tabular}




\begin{tabular}{llrrrrr} 
concrete*Time & $\mathrm{BL}$ & 0 &. &. &. &. \\
InstrucE & & -0.1442 & 0.08333 & 1279 & -1.73 & 0.0839 \\
InstrucE*Time & 0T2 & -0.1676 & 0.1385 & 1279 & -1.21 & 0.2267 \\
InstrucE*Time & 0T3 & -0.4065 & 0.1646 & 1279 & -2.47 & 0.0136 \\
InstrucE*Time & 0T4 & -0.4602 & 0.2101 & 1279 & -2.19 & 0.0287 \\
InstrucE*Time & BL & 0 &. &. &. &. \\
\hline
\end{tabular}

Table 5

Covariance Parameter Estimates: Concreteness on Expressive Outcomes Covariance Parameter Estimates

\begin{tabular}{llllll}
\hline Cov Parm & Subject & Estimate & $\begin{array}{l}\text { Standard } \\
\text { Error }\end{array}$ & Z Value & $\operatorname{Pr}>$ Z \\
Intercept & sch_id & 7.7529 & 2.1988 & 3.43 & 0.0003 \\
Intercept & Clas_id(sch_id) & 2.1838 & 1.1547 & 1.89 & 0.0293 \\
Intercept & stuID(sch_id*clas_ & 11.3537 & 1.7609 & 6.45 & $<.0001$ \\
& id) & 43.0652 & 1.6716 & 25.76 & $<.0001$ \\
Residual & & & & & \\
\hline
\end{tabular}

Table 6

Regression Table of Concreteness on Receptive Outcomes

Solution for Fixed Effects

\begin{tabular}{|c|c|c|c|c|c|c|}
\hline Effect & Time & Estimate & $\begin{array}{l}\text { Standard } \\
\text { Error }\end{array}$ & $\mathrm{DF}$ & t Value & $\operatorname{Pr}>|t|$ \\
\hline Intercept & & 3.9087 & 1.2988 & 46 & 3.01 & 0.0042 \\
\hline Time & $0 \mathrm{~T} 2$ & 7.5198 & 4.2262 & 919 & 1.78 & 0.0755 \\
\hline Time & $0 \mathrm{~T} 3$ & -2.6063 & 4.9800 & 919 & -0.52 & 0.6009 \\
\hline Time & $0 \mathrm{~T} 4$ & -2.3122 & 5.5497 & 919 & -0.42 & 0.6770 \\
\hline Time & $\mathrm{BL}$ & 0 & & & & \\
\hline concreteR & & 0.2011 & 0.3876 & 919 & 0.52 & 0.6039 \\
\hline concreteR ${ }^{*}$ Time & $0 \mathrm{~T} 2$ & 1.2706 & 1.2274 & 919 & 1.04 & 0.3009 \\
\hline concreteR ${ }^{*}$ Time & $0 \mathrm{~T} 3$ & 1.8720 & 1.4350 & 919 & 1.30 & 0.1924 \\
\hline concreteR ${ }^{*}$ Time & $0 \mathrm{~T} 4$ & 2.5121 & 1.5886 & 919 & 1.58 & 0.1141 \\
\hline concreteRTime & $\mathrm{BL}$ & 0 & & & & \\
\hline InstrucR & & 0.01387 & 0.03673 & 919 & 0.38 & 07057 \\
\hline InstrucR*Time & $0 \mathrm{~T} 2$ & -0.2340 & 0.1209 & 919 & -1.93 & 0.0533 \\
\hline InstrucR*Time & $0 \mathrm{~T} 3$ & 0.4183 & 0.1467 & 919 & 2.85 & 0.0044 \\
\hline InstrucR*Time & $0 \mathrm{~T} 4$ & 0.2603 & 0.1952 & 919 & 1.33 & 0.1826 \\
\hline InstrucR*Time & $\mathrm{BL}$ & 0 & & & & \\
\hline
\end{tabular}


Table 7

Covariance Parameter Estimates: Concreteness on Receptive Outcomes Covariance Parameter Estimates

\begin{tabular}{llllll}
\hline Cov Parm & Subject & Estimate & $\begin{array}{l}\text { Standard } \\
\text { Error }\end{array}$ & Z Value & Pr $>$ Z \\
Intercept & sch_id & 1.4680 & 0.4506 & 3.26 & 0.0003 \\
Intercept & Clas_id(sch_id) & 0.4188 & 0.1616 & 2.59 & 0.0048 \\
Intercept & stuID(sch_id*clas_ & 1.5050 & 0.2197 & 6.86 & $<.0001$ \\
& id) & 3.9605 & 0.1808 & 21.91 & $<.0001$ \\
Residual & & & & & \\
\hline
\end{tabular}

\section{Influence of Concreteness Controlling for Instructional Sequence}

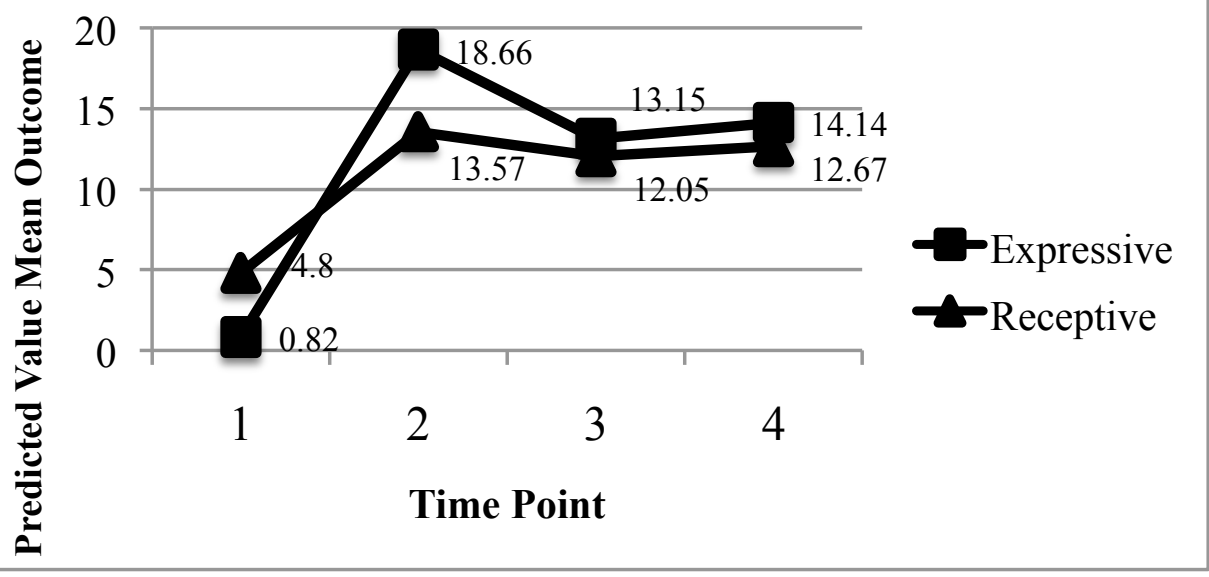

Figure 6. The influence of concreteness on expressive (square) and receptive (triangle) target vocabulary measures over time (i.e., beginning of kindergarten, end of kindergarten, end of $1^{\text {st }}$ grade, and mid-year $2^{\text {nd }}$ grade) after controlling for the week of the intervention in which the target word was introduced/taught.

When controlling for the week of the intervention in which the target word was introduced/taught, the influence of word syllable count on expressive target word vocabulary outcome scores was statistically significant at time point $2(P<.001)$. Again, when controlling for the week of the intervention in which the target word was 
introduced/taught, the influence of word syllable count on receptive target word vocabulary outcome scores, however, was statistically significant at all time points (time point $2: P<.001$; time point $3 P=.001$; time point $4: P=.02$ ). Table 8 and Table 10 show the results of the final model (i.e., the three-level mixed model) for the effect of syllable count on Expressive and Receptive vocabulary outcomes, respectively. Table 9 and Table 11 present the covariance parameter estimates for the effect of syllable count on expressive and Receptive vocabulary outcomes, respectively, which included adjustments for individuals nested within classroom, and as well as classrooms nested within schools. Figure 7 shows this influence of syllable count on vocabulary outcomes in graphic form.

Table 8

Regression Table of Syllable Count on Expressive Outcomes Solution for Fixed Effects

\begin{tabular}{|c|c|c|c|c|c|c|}
\hline Effect & Time & Estimate & $\begin{array}{l}\text { Standard } \\
\text { Error }\end{array}$ & $\overline{\mathrm{DF}}$ & t Value & $\operatorname{Pr}>|t|$ \\
\hline Intercept & & 8503 & 0.5380 & 47 & 1.58 & 0.1207 \\
\hline Time & 0T2 & 8.4593 & 1.3199 & 1279 & 6.41 & $<.0001$ \\
\hline Time & $0 \mathrm{~T} 3$ & 11.9148 & 2.0740 & 1279 & 5.74 & $<.0001$ \\
\hline Time & 0T4 & 18.8470 & 3.7095 & 1279 & 5.08 & $<.0001$ \\
\hline Time & $\mathrm{BL}$ & 0 & & & & \\
\hline syllableE & & 0.5654 & 0.4741 & 1279 & 1.19 & 0.2332 \\
\hline syllableE*Time & 0T2 & 5.5329 & 0.8609 & 1279 & 6.43 & $<.0001$ \\
\hline syllableE *Time & 0T3 & 1.1437 & 1.0849 & 1279 & 1.05 & 0.2920 \\
\hline syllableE *Time & 0T4 & -1.3948 & 1.9433 & 1279 & -0.72 & 0.4731 \\
\hline syllableE *Time & BL & 0 & & & & \\
\hline InstrucE & & -0.04084 & 0.06446 & 1279 & -0.63 & 0.5264 \\
\hline InstrucE*Time & 0T2 & -0.1862 & 0.1138 & 1279 & -1.64 & 0.1020 \\
\hline InstrucE*Time & 0T3 & -0.3108 & 0.1362 & 1279 & -2.28 & 0.0226 \\
\hline InstrucE*Time & 0T4 & -0.3806 & 0.2011 & 1279 & -1.89 & 0.0586 \\
\hline InstrucE*Time & BL & 0 & & & & \\
\hline
\end{tabular}


Table 9

Covariance Parameter Estimates: Syllable Count on Expressive Outcomes Covariance Parameter Estimates

\begin{tabular}{llllll}
\hline Cov Parm & Subject & Estimate & $\begin{array}{l}\text { Standard } \\
\text { Error }\end{array}$ & Z Value & $\operatorname{Pr}>$ Z \\
Intercept & sch_id & 7.1911 & 2.1308 & 3.37 & 0.0004 \\
Intercept & Clas_id(sch_id) & 2.6069 & 1.1776 & 2.21 & 0.0131 \\
Intercept & stuID(sch_id*clas_ & 10.9523 & 1.7434 & 6.28 & $<.0001$ \\
& id) & 42.8363 & 1.6659 & 25.71 & $<.0001$ \\
Residual & & & & & \\
\hline
\end{tabular}

Table 10

Regression Table of Syllable Count on Receptive Outcomes Solution for Fixed Effects

\begin{tabular}{|c|c|c|c|c|c|c|}
\hline Effect & Time & Estimate & $\begin{array}{l}\text { Standard } \\
\text { Error }\end{array}$ & $\mathrm{DF}$ & t Value & $\operatorname{Pr}>|t|$ \\
\hline Intercept & & 2.0406 & 2.4382 & 46 & 0.84 & 0.4069 \\
\hline Time & $0 \mathrm{~T} 2$ & 53.2369 & 8.0974 & 859 & 6.57 & $<.0001$ \\
\hline Time & $0 \mathrm{~T} 3$ & 10.3831 & 8.7909 & 859 & 1.18 & -.2379 \\
\hline Time & 0T4 & 19.7276 & 12.9237 & 859 & 1.53 & -.1273 \\
\hline Time & $\mathrm{BL}$ & 0 & & & & \\
\hline syllableR & & -0.5078 & 1.1374 & 859 & -0.45 & 0.6554 \\
\hline syllableR*Time & 0T2 & -14.1268 & 3.9277 & 859 & -3.60 & 0.0003 \\
\hline syllableR *Time & $0 \mathrm{~T} 3$ & -1.9475 & 4.2923 & 859 & -0.45 & 0.6501 \\
\hline syllableR *Time & 0T4 & -5.5434 & 5.5399 & 859 & -1.00 & 0.3173 \\
\hline syllableR *Time & $\mathrm{BL}$ & 0 & & & . & \\
\hline InstrucR & & -0.04870 & 0.1243 & 859 & -0.39 & 0.6953 \\
\hline InstrucR*Time & $0 \mathrm{~T} 2$ & -0.7364 & 0.3958 & 859 & -1.86 & 0.0628 \\
\hline InstrucR*Time & $0 \mathrm{~T} 3$ & 0.5413 & 0.4846 & 859 & 1.12 & 0.2643 \\
\hline InstrucR*Time & 0T4 & 0.3983 & 0.6600 & 859 & 0.60 & 0.5463 \\
\hline InstrucR*Time & BL & 0 & & & & \\
\hline
\end{tabular}

Table 11

Covariance Parameter Estimates: Syllable Count on Receptive Outcomes Covariance Parameter Estimates

\begin{tabular}{llllll}
\hline Cov Parm & Subject & Estimate & $\begin{array}{l}\text { Standard } \\
\text { Error }\end{array}$ & Z Value & $\operatorname{Pr}>$ Z \\
Intercept & sch_id & 14.9057 & 4.4813 & 3.33 & 0.0004 \\
Intercept & Clas_id(sch_id) & 6.5377 & 2.1465 & 3.05 & 0.0012 \\
Intercept & stuID(sch_id*clas_ & 15.6543 & 2.6805 & 5.84 & $<.0001$ \\
& id) & & & & \\
Residual & & 45.6453 & 2.2093 & 20.66 & $<.0001$ \\
\hline
\end{tabular}




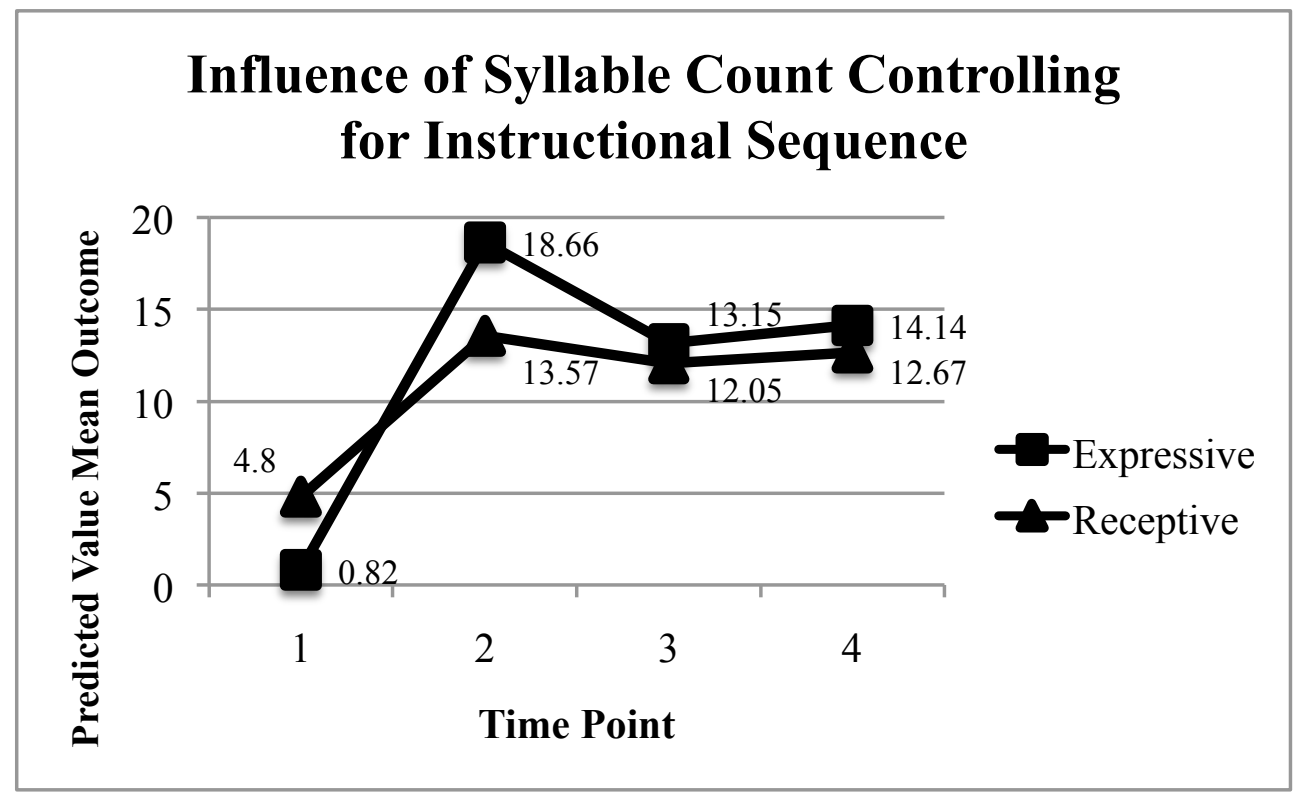

Figure 7. The influence of syllable count on expressive (square) and receptive (triangle) target vocabulary word outcomes scores over time (i.e., beginning of kindergarten, end of kindergarten, end of $1^{\text {st }}$ grade, and mid-year $2^{\text {nd }}$ grade) after controlling for the week of the intervention in which the target vocabulary word was introduced/taught. 


\section{CHAPTER 5}

\section{CONCLUSION}

Differences in early exposure to oral language contribute to differences in vocabulary knowledge, leaving too many children with inadequate early vocabularies

(Hart \& Risley, 1995). This is disconcerting because children entering school with low levels of vocabulary skills are known to be at risk for developing reading difficulties as vocabulary skills are among the major foundational reading skills (NICDH, 2000). Efforts to boost children's vocabulary knowledge through delivery of merely wholeclass vocabulary instruction, unfortunately only puts the at-risk children further behind. According to findings of vocabulary intervention studies, these at-risk children benefit from evidence-based, small-group vocabulary intervention (Cuticelli et al., 2015).

This evidence-based, small-group vocabulary intervention features a somewhat standard set of strategies for teaching the varied Tier 2 words such as pre-introduction to target vocabulary words, storybook reading, providing child-friendly definitions, showing picture examples, having the child practice using the words, and reviewing the words (Beck et al., 2013). Interestingly, though it is known that in general, different word properties contribute to word learning difficulty, current evidencebased vocabulary instructional methods do not incorporate such findings (Breland, 1996; De Groot \& Keijzer, 2000; Laufer, 1990b). The use of standard or uniform instructional methods across all target Tier 2 vocabulary words suggests that the targeted words are equally learnable. Given that word difficulty evidence suggests that 
such words are not equally learnable, research inquiry in this area is undoubtedly warranted. Improving the efficiency of already effective evidence-based vocabulary instructional methods could make such supports more accessible and practical in the classroom.

The specific purpose of the current study was to examine how word properties, concreteness and syllable count, influence at-risk children's Tier 2 vocabulary word learning in an effort to initiate evidence-based exploration of how tailoring vocabulary instructional methods based on word difficulty evidence could impact word learning and instructional efficiency. Such inquiry is important for supporting the most disadvantaged students to build the skills necessary to become accomplished readers, as well as potentially improving the efficiency and practicality of current standard methods.

\section{Summary of Results and Implications}

The current study examined three hypotheses regarding the relationship between Tier 2 target vocabulary word concreteness and syllable count, and expressive and receptive target vocabulary word learning outcomes, as well as the influence of the length of time (in weeks) between instruction and assessment of target words (i.e., instructional sequence) on expressive and receptive target vocabulary word outcomes. First, it was hypothesized that target word concreteness would significantly predict short-term and long-term expressive and receptive target vocabulary word learning outcomes such that the degree of concreteness would correlate with outcome scores. Second, it was hypothesized that target word syllable count would significantly predict short-term and long-term expressive and receptive 
target vocabulary word learning outcomes such that the syllable count would negatively correlate with the outcome scores. Lastly, it was hypothesized that the instructional sequencing (i.e., the week of the intervention in which words were introduced/taught) of the target vocabulary words would help explain the influence of concreteness and syllable count on short- and long-term expressive and receptive target word learning outcomes.

The findings of the current study provide evidence that the word property, concreteness, significantly predicts the short-term expressive Tier 2 target vocabulary learning outcomes of at-risk children in kindergarten. When controlling for instructional sequence, however, concreteness was shown to significantly predict short- and long-term expressive learning outcomes. In other words, the current study demonstrates that concreteness significantly predicts short- and long-term expressive learning outcomes regardless of how much time passes between instruction and assessment (up to 20 weeks) of target words. Specifically, this finding suggests that the greater degree to which a word is concrete, the greater the expressive outcome score. Concreteness was not shown to predict receptive Tier 2 target vocabulary learning outcomes with or without controlling for instructional sequence.

The implications for these findings are dependent on the learning or assessment goal (i.e., breadth versus depth). If, for example, the educator desires that students be able to demonstrate breadth (i.e., quantity) of target vocabulary knowledge, and therefore assesses knowledge using a receptive measure, concreteness of the target vocabulary words may not need to be considered during target vocabulary word instruction. Alternatively, if the educator desires that students be able to 
demonstrate depth (i.e., qualitative) of target vocabulary knowledge, and therefore assesses knowledge using an expressive measure, concreteness should, according to these results, inform target vocabulary word instruction because the less concrete a word is, the more difficult it is for the child to learn, express, and/or retain short- and long-term.

The findings also evidence that the word property, syllable count, significantly predicts short-term expressive Tier 2 target vocabulary learning outcomes of at-risk children in kindergarten. When controlling for instructional sequence, syllable count still significantly predicts short-term expressive learning outcomes. In other words, the current study demonstrates that syllable count significantly predicts short-term expressive learning outcomes regardless of how much time passes between instruction and assessment (up to 20 weeks) of target words. Specifically, this finding suggests that the greater number of syllables in a target word, the greater the expressive outcome score on a short-term assessment.

Syllable count was also shown to predict short- and long-term receptive learning outcomes. When controlling for instructional sequence, syllable count was, again, shown to predict short- and long-term receptive learning outcomes. Contrary to the relationship between syllable count and expressive scores, syllable count was, however, shown to be negatively correlated with receptive learning outcomes, such that the fewer syllables in the target word, the greater the receptive outcome score. These results of syllable count, which suggest that a target word's number of syllables is predictive of outcomes that are different for expressive (short-term) and receptive (short- and long-term) target word outcome learning could be at least 
partially explained by the difference in cognitive demands required by each type of assessment. The expressive outcome measure requires more in-depth expressive abilities about each word, whereas the receptive outcome measure requires less indepth knowledge about the word, but rather recognition of the concept in picture form. In the word difficulty literature, syllable count, as an indicator of word length, is suggested to negatively correlate with ease of learning (Stahl \& Nagy, 2006); however, Laufer (1990b) found that for language learners, word length correlates with word learning difficulty only until the second language proficiency improves, at which time, word length was not shown to correlate with difficulty. This finding is important given the population of language learners among children with at-risk vocabulary skills. Lexical processing evidence, on the other hand, suggests that syllable count positively correlates with ease of learning due to the word's increase in prominence, or perceived emphasis as compared to words with fewer syllables (Streefkerk, 2002).

As with the implications for the results of concreteness, implications for these findings on syllable count are also dependent on the learning and/or assessment goal, that is, breadth versus depth in vocabulary knowledge. If the educator desires that students be able to demonstrate breadth (i.e., quantity) of target vocabulary knowledge, and therefore assesses knowledge using a receptive measure, the findings of the current study suggest that the syllable count of the target vocabulary words could be relevant during target vocabulary word instruction as lower syllable count is shown to predict ease of learning and/or receptive recall. Here, it could be hypothesized (and subsequently experimentally tested) that providing greater 
instructional attention to target words of greater syllable count, the greater the receptive learning outcomes.

If, instead, the goal of the educator is for students to be able to demonstrate depth (i.e., qualitative) of target vocabulary knowledge, and therefore assesses knowledge using an expressive measure, syllable count should also inform target vocabulary word instruction because, according to these results, the greater the syllable count, the easier it is for the child to learn, express, and/or retain short-term expressive knowledge. An experimental study examining the degree to which greater instructional attention to target words with lower syllable counts predicts ease of expressive word learning would provide further evidence about such implications.

The educator's ultimate vocabulary learning goals are of clear importance when it comes to using the current study's word difficulty evidence to inform vocabulary instruction. Given that expressive vocabulary knowledge is suggested to be a stronger predictor of later reading achievement than is receptive vocabulary knowledge (Snow, Burns, \& Griffin, 1998), and that receptive vocabulary is already often larger than one's expressive vocabulary (NRP, 2000), it may be important for educators to focus on strengthening students' expressive vocabularies.

\section{Limitations and Future Directions}

Several limitations of the current study relate to measurement methods. First, the Receptive Target Word Vocabulary Measure (RTWVM), which is a picture recognition task, allows a $25 \%$ chance of guessing the correct answer. Given that the Expressive Target Word Vocabulary Measure (ETWVM) requires more in-depth 
knowledge of target vocabulary words as compared to the RTWVM in order to achieve similar scores, and that the former does not allow the same chance of guessing correctly, content validity may be affected.

Additionally, the Brysbaert et al. (2014) reference list used to calculate target word concreteness poses at least two limitations. First, the reported concreteness values were reported by adults, who likely possess greater word knowledge than children in kindergarten, which could influence their concreteness rating in a way that would not be representative of the way in which children perceive the concreteness of words. A second limitation of this measure is that some of the rated words that appear in the current study are homonyms (i.e., words that share the same pronunciation but have different meanings, regardless of spelling) (e.g., fleet, hatch, labor) and, therefore, the raters may have rated the concreteness of words that were taught using a different meaning than in the current study.

Educators and developing readers alike would benefit from a more complete understanding of how Tier 2 vocabulary word difficulty can be utilized to improve vocabulary instruction and, therefore, vocabulary learning. Future research should investigate why concreteness is predictive of expressive learning but not receptive learning, as well as the effects of considering target word concreteness during target vocabulary word instruction in order to help children better learn less concrete (i.e., abstract) words. Researchers should also examine the underlying causes of differences between the role of target word syllable count in expressive and receptive vocabulary learning/recall. Another important factor to explore is the influence of English 
Language Learner status on the influence of concreteness and syllable count on vocabulary learning.

It is important to note that word difficulty data should not be utilized as a means of avoiding the teaching of more difficult-to-learn vocabulary words. Tier 2 words, which vary across word properties and may require diverse instructional strategies to improve learning outcomes, are especially important for children with at-risk vocabularies to learn for supporting strong reading development. 


\section{APPENDIX A}

EVI Instructional Sequence for Weeks 1-20

\begin{tabular}{|c|c|c|}
\hline Week & $\begin{array}{l}\text { Elements of Reading: } \\
\text { Vocabulary (EOR-V) } \\
\text { (All Groups) } \\
\text { Tier } 1 \text { Target Words }\end{array}$ & $\begin{array}{l}\text { EVI Intervention } \\
\text { (Tx Group only) } \\
\text { Tier } 2 \text { Target Words }\end{array}$ \\
\hline \multirow[t]{5}{*}{1} & Comforting & Comforting \\
\hline & Fleet & Fleet \\
\hline & Glimmer & Glimmer \\
\hline & Lively & \\
\hline & Expression & \\
\hline \multirow[t]{5}{*}{2} & Drenched & Drenched \\
\hline & Gorgeous & Gorgeous \\
\hline & Peculiar & Peculiar \\
\hline & Linger & \\
\hline & Vain & \\
\hline \multirow[t]{5}{*}{3} & Glance & Glance \\
\hline & Timid & Timid \\
\hline & Frantic & Frantic \\
\hline & Reluctant & \\
\hline & Intimidated & \\
\hline \multirow[t]{5}{*}{4} & Journey & Journey \\
\hline & Glide & Glide \\
\hline & Soar & Soar \\
\hline & Adventure & \\
\hline & Roam & \\
\hline \multirow[t]{3}{*}{5} & Stumble & Stumble \\
\hline & Pursue & Pursue \\
\hline & Collide & Collide \\
\hline
\end{tabular}




\begin{tabular}{|c|c|c|}
\hline & Lounge & \\
\hline & Absurd & \\
\hline 6 & Alert & Alert \\
\hline & Narrow & Narrow \\
\hline & Wavy & Wavy \\
\hline & Swirl & \\
\hline & Relief & \\
\hline 7 & Active & Active \\
\hline & Describe & Describe \\
\hline & Broad & Broad \\
\hline & Whisk & \\
\hline & Scamper & \\
\hline 8 & Ancient & Ancient \\
\hline & Mischievous & Mischievous \\
\hline & Observe & Observe \\
\hline & Track & \\
\hline & Hefty & \\
\hline 9 & Discouraged & Discouraged \\
\hline & Hesitate & Hestitate \\
\hline & Desire & Desire \\
\hline & Respect & \\
\hline & Extraordinary & \\
\hline 10 & Splendid & Splendid \\
\hline & Celebrate & Celebrate \\
\hline & Option & Option \\
\hline & Village & \\
\hline & Appreciate & \\
\hline 11 & Amble & Amble \\
\hline & Displeased & Displease \\
\hline
\end{tabular}




\begin{tabular}{|c|c|c|}
\hline & Request & Request \\
\hline & Bare & \\
\hline & Fetch & \\
\hline 12 & Snare & Snare \\
\hline & Nestle & Nestle \\
\hline & Perilous & Perilous \\
\hline & Pounce & \\
\hline & Unlikely & \\
\hline 13 & Sprinkle & Sprinkle \\
\hline & Solitude & Solitude \\
\hline & Muddle & Muddle \\
\hline & Progression & \\
\hline & Expectation & \\
\hline 14 & Enormous & Enormous \\
\hline & Sway & Sway \\
\hline & \begin{tabular}{|l} 
Struggle \\
\end{tabular} & \begin{tabular}{|l|} 
Struggle \\
\end{tabular} \\
\hline & Delighted & \\
\hline & Cooperate & \\
\hline 15 & Baffled & Baffled \\
\hline & Startle & Startle \\
\hline & Slumber & Slumber \\
\hline & Plea & \\
\hline & Flustered & \\
\hline 16 & Creak & Creak \\
\hline & Stalk & Stalk \\
\hline & Communicate & Communicate \\
\hline & Chatter & \\
\hline & Action & \\
\hline 17 & Scraggly & \begin{tabular}{|l} 
Scraggly \\
\end{tabular} \\
\hline
\end{tabular}




\begin{tabular}{|c|c|c|}
\hline & Prod & Prod \\
\hline & \begin{tabular}{|l|} 
Plump \\
\end{tabular} & Plump \\
\hline & Witty & \\
\hline & Aware & \\
\hline 18 & Romp & Romp \\
\hline & Gather & Gather \\
\hline & \begin{tabular}{|l} 
Creative \\
\end{tabular} & Creative \\
\hline & Fad & \\
\hline & Entertain & \\
\hline 19 & Slime & Slime \\
\hline & Hatch & Hatch \\
\hline & Haven & Haven \\
\hline & Slither & \\
\hline & Eager & \\
\hline 20 & Beacon & Beacon \\
\hline & Labor & Labor \\
\hline & Memorable & Memorable \\
\hline & Survey & \\
\hline & Mammoth & \\
\hline
\end{tabular}




\section{APPENDIX B}

\section{EXPRESSIVE TARGET WORDS}

\section{DIRECTIONS:}

I'm going to ask you about some words and I want you to tell me what they mean. So if I said, "Tell me what the word cat means," you could say, "A cat is a furry animal that says meow."

Now you try: Tell me what the word dog means.

\begin{tabular}{|l|l|}
\hline Question & Response (verbatim) \\
\hline $\begin{array}{l}\text { 1. Tell me what the word } \\
\text { fleeans. }\end{array}$ & \\
\hline $\begin{array}{l}\text { 2. Tell me what the word } \\
\text { glimmer means. }\end{array}$ & \\
\hline $\begin{array}{l}\text { 3. Tell me what the word } \\
\text { drenched means. }\end{array}$ & \\
\hline $\begin{array}{l}\text { 4. Tell me what the word } \\
\text { peculiar means. }\end{array}$ & \\
\hline $\begin{array}{l}\text { 5. Tell me what the word } \\
\text { timid means. }\end{array}$ & \\
\hline
\end{tabular}

6. Tell me what the word stumble means. 


\begin{tabular}{|l|l|}
\hline $\begin{array}{l}\text { 7. Tell me what the word } \\
\text { collide means. }\end{array}$ \\
\hline $\begin{array}{l}\text { 8. Tell me what the word } \\
\text { narrow means. }\end{array}$ \\
\hline $\begin{array}{l}\text { 9. Tell me what the word } \\
\text { active means. }\end{array}$ \\
\hline $\begin{array}{l}\text { 10. Tell me what the } \\
\text { word ancient means. }\end{array}$ \\
$\begin{array}{l}\text { 12. Tell me what the } \\
\text { word desire means. }\end{array}$ \\
$\begin{array}{l}\text { 11. Tell me what the } \\
\text { word mischievous } \\
\text { means. }\end{array}$ \\
\hline
\end{tabular}

13. Tell me what the word option means. 


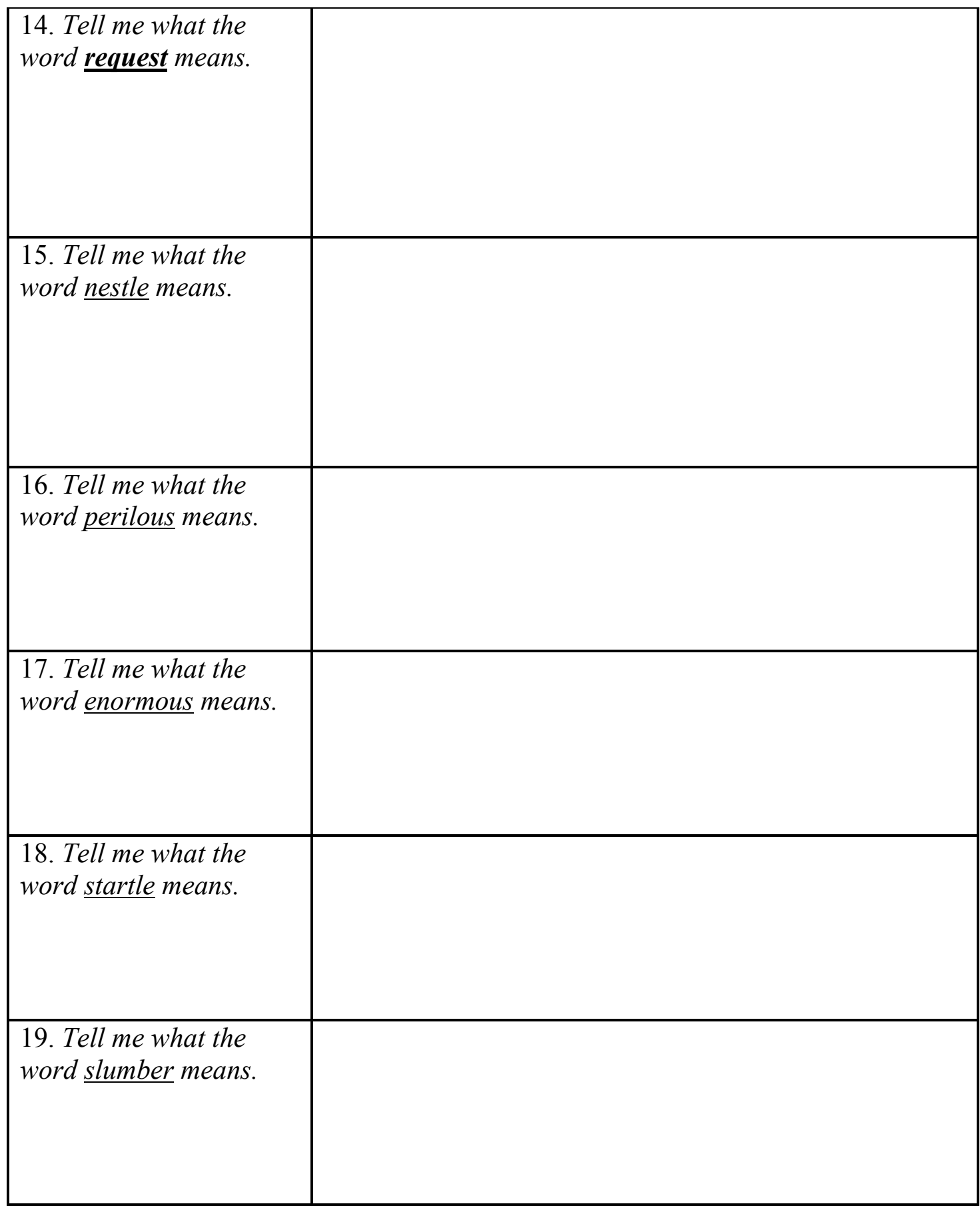

20. Tell me what the word stalk means. 


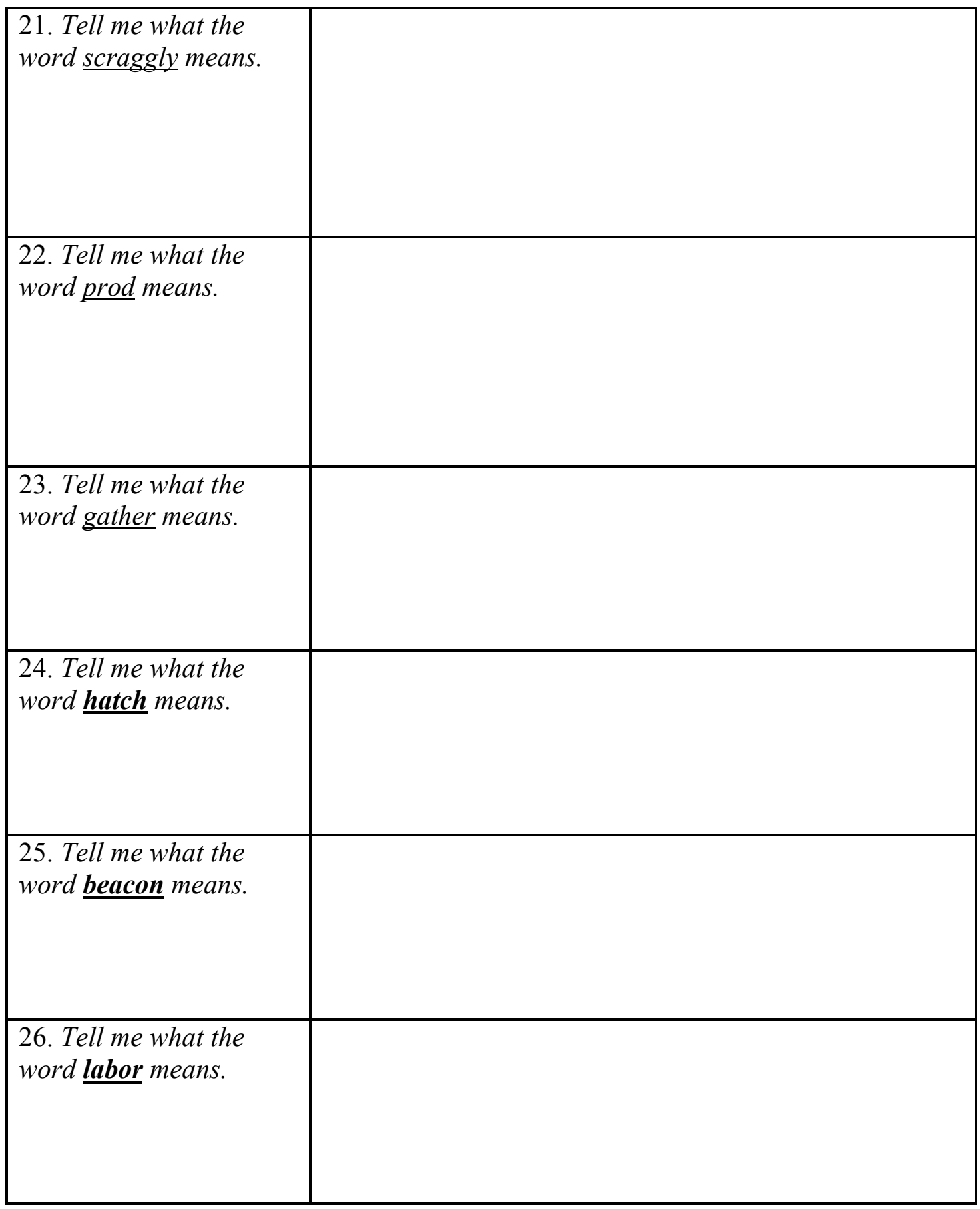


SAY: Now I'm going to show you some pictures. I want to you point to the picture that shows the word I say.

\begin{tabular}{|c|c|c|}
\hline Question & Response & \\
\hline \multirow[t]{2}{*}{$\begin{array}{l}\text { Point to the picture that shows } \\
\text { narrow. } \\
\text { (show stimulus sheet } 1 \text { ) }\end{array}$} & 1 & narrow \\
\hline & 3 & 4 \\
\hline \multirow[t]{2}{*}{$\begin{array}{l}\text { Point to the picture that shows } \\
\text { gather. } \\
\text { (show stimulus sheet } 2 \text { ) }\end{array}$} & 1 & 2 \\
\hline & 3 & gather \\
\hline \multirow[t]{2}{*}{$\begin{array}{l}\text { Point to active. } \\
\text { (show stimulus sheet } 3 \text { ) }\end{array}$} & 1 & active \\
\hline & 3 & 4 \\
\hline \multirow[t]{2}{*}{$\begin{array}{l}\text { Point to enormous. } \\
\text { (show stimulus sheet 4) }\end{array}$} & 1 & 2 \\
\hline & 3 & enormous \\
\hline \multirow[t]{2}{*}{$\begin{array}{l}\text { Point to stalk. } \\
\text { (show stimulus sheet 5) }\end{array}$} & stalk & 2 \\
\hline & 3 & 4 \\
\hline \multirow[t]{2}{*}{$\begin{array}{l}\text { Point to fleet. } \\
\text { (show stimulus sheet 6) }\end{array}$} & fleet & 2 \\
\hline & 3 & 4 \\
\hline \multirow[t]{2}{*}{$\begin{array}{l}\text { Point to peculiar. } \\
\text { (show stimulus sheet } 7 \text { ) }\end{array}$} & peculiar & 2 \\
\hline & 3 & 4 \\
\hline $\begin{array}{l}\text { Point to startle. } \\
\text { (show stimulus sheet } 8 \text { ) }\end{array}$ & 1 & 2 \\
\hline
\end{tabular}




\begin{tabular}{|c|c|c|}
\hline & 3 & Startle \\
\hline \multirow[t]{2}{*}{ 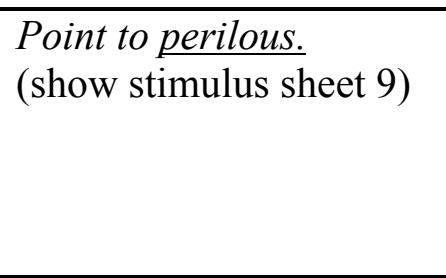 } & 1 & 2 \\
\hline & 3 & perilous \\
\hline \multirow[t]{2}{*}{$\begin{array}{l}\text { Point to prod. } \\
\text { (show stimulus sheet } 10 \text { ) }\end{array}$} & 1 & prod \\
\hline & 3 & 4 \\
\hline \multirow[t]{2}{*}{$\begin{array}{l}\text { Point to slumber. } \\
\text { (show stimulus sheet 11) }\end{array}$} & 1 & 2 \\
\hline & slumber & 4 \\
\hline \multirow[t]{2}{*}{$\begin{array}{l}\text { Point to nestle. } \\
\text { (show stimulus sheet } 12 \text { ) }\end{array}$} & 1 & 2 \\
\hline & 3 & nestle \\
\hline \multirow[t]{2}{*}{ 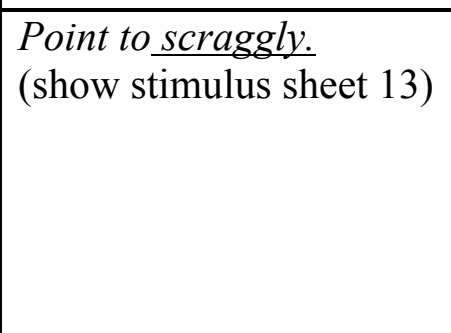 } & 1 & 2 \\
\hline & 3 & scraggly \\
\hline \multirow[t]{2}{*}{$\begin{array}{l}\text { Point to stumble. } \\
\text { (show stimulus sheet 14) }\end{array}$} & 1 & 2 \\
\hline & stumble & 4 \\
\hline \multirow[t]{2}{*}{$\begin{array}{l}\text { Point to ancient. } \\
\text { (show stimulus sheet } 15 \text { ) }\end{array}$} & 1 & 2 \\
\hline & 3 & ancient \\
\hline $\begin{array}{l}\text { Point to drenched. } \\
\text { (show stimulus sheet 16) }\end{array}$ & 1 & 2 \\
\hline
\end{tabular}




\begin{tabular}{|l|l|l|} 
& drenched & 4 \\
\hline
\end{tabular}




\section{BIBLIOGRAPHY}

Anderson, R.C., \& Freebody, P. (1981). Vocabulary knowledge. In J. Guthrie (Ed.), Comprehension and teaching: Research reviews (pp. 77-117). Newark, DE: International Reading Association.

Apthorp, H. S. (2006). Effects of a supplemental vocabulary program in third-grade reading/language arts. The Journal of Educational Research, 100(2), 67-79.

Baddeley, A.D. (1997). Human memory: theory and practice (revised ed.). East Sussex: Psychology Press.

Balota, D. A., Yap, M. J., Hutchison, K. A., Cortese, M. J., Kessler, B., Loftis, B., Neely, J.H., Nelson, D.L., Simpson, G.B., \& Treiman, R. (2007). The English lexicon project. Behavior research methods, 39(3), 445-459.

Beck, I.L., \& McKeown, M.G. (2004). Elements of reading: Vocabulary. Austin, TX: Teck-Vaughn.

Beck, I. L., McKeown, M. G., \& Kucan, L. (2013). Bringing words to life: Robust vocabulary instruction. Guilford Press.

Beck, I. L., McKeown, M. G., \& Omanson, R. C. (1987). The effects and uses of diverse vocabulary instructional techniques. In M. McKeown \& M. Curtis (Eds.), The nature of vocabulary acquisition (pp. 147-163). Hillsdale, NJ: Lawrence Erlbaum.

Biemiller, A. (2001). Teaching vocabulary: Early, direct, and sequential. American Educator, 25(1), 24-28.

Biemiller, A. (2003). Vocabulary: Needed if more children are to read well. Reading Psychology, 24(3-4), 323-335. 
Biemiller, A. (2012). Teaching vocabulary in the primary grades: Vocabulary instruction needed. In E.J. Kame'enui \& J.F. Baumann (Ed.), Vocabulary instruction: Research to practice (pp. 34-50). New York, NY: The Guilford Press.

Biemiller, A., \& Boote, C. (2006). An effective method for building meaning vocabulary in primary grades. Journal of Educational Psychology, 98(1), 44.

Biemiller, A., \& Slonim, N. (2001). Estimating root word vocabulary growth in normative and advantaged populations: Evidence for a common sequence of vocabulary acquisition. Journal of Educational Psychology, 93(3), 498.

Breland, H. M. (1996). Word frequency and word difficulty: A comparison of counts in four corpora. Psychological Science, 7(2), 96-99.

Brysbaert, M., Warriner, A. B., \& Kuperman, V. (2014). Concreteness ratings for 40 thousand generally known English word lemmas. Behavior research methods, 46(3), 904-911.

Chall, J. S., Jacobs, V. A., \& Baldwin, L. E. (1990). The reading crisis: Why poor children fall behind. Cambridge, MA: Harvard University Press.

Coyne, M. D., Kame'enui, E. J., \& Simmons, D. C. (2001). Prevention and intervention in beginning reading: Two complex systems. Learning Disabilities Research \& Practice, 16(2), 62-73.

Coyne, M. D., McCoach, D. B., \& Kapp, S. (2007). Vocabulary intervention for kindergarten students: Comparing extended instruction to embedded instruction and incidental exposure. Learning Disability Quarterly, 30(2), 74-88. 
Coyne, M. D., McCoach, D. B., Loftus-Rattan, S., Baker, D. L., \& Santoro, L. E. (2011-2016). Project EVI: Early vocabulary intervention (R324A110135).

Washington, DC: U.S. Department of Education, Institute of Education Sciences, Reading and Writing Research- Special Education Research.

Coyne, M. D., McCoach, D. B., Loftus, S., Zipoli Jr, R., \& Kapp, S. (2009). Direct vocabulary instruction in kindergarten: Teaching for breadth versus depth. The Elementary School Journal, 110(1), 1-18.

Crystal, D. (1995). In search of English: a traveller's guide. ELT Journal, 49(2), $107-$ 121.

Cummins, J. (1994). The acquisition of English as a second language. In K. Spangenberg-Urbschat \& R. Pritchard (Eds.), Kids come in all languages: Reading instruction for ESL students (pp. 36-62). Newark, DE: International Reading Association.

Cuticelli, M., Coyne, M. D., Ware, S. M., Oldham, A., \& Loftus Rattan, S. (2015). Improving vocabulary skills of kindergarten students through a multi-tier instructional approach. Intervention in School and Clinic, 50(3), 150-156.

Dale, E. (1965). Vocabulary measurement: Techniques and major findings. Elementary English, 42, 895-901.

Davis, F.B., (1944). Fundamental factors of comprehension in reading. Psychometrika, 9, 185-197.

De Groot, A., \& Keijzer, R. (2000). What is hard to learn is easy to forget: The roles of word concreteness, cognate status, and word frequency in foreign-language vocabulary learning and forgetting. Language Learning, 50(1), 1-56. 
Dolch, E. W. (1932). Testing word difficulty. The Journal of Educational Research, $26(1), 22-27$.

Dunn, L.M. \& Dunn, L.M. (2007). Peabody Picture Vocabulary Test, Fourth Edition. Circle Pines, MM: American Guidance Service.

Hart, B., \& Risley, T. (1995). Meaningful differences in the everyday lives of young American children. Baltimore: Paul H. Brookes.

Hayes, D. P., \& Ahrens, M. G. (1988). Vocabulary simplification for children: A special case of "motherese"?. Journal of child language, 15(02), 395-410.

Herman, P. A., Anderson, R. C., Pearson, P. D., \& Nagy, W. E. (1987). Incidental acquisition of word meaning from expositions with varied text features. Reading Research Quarterly, 263-284.

Hoffman, J. L., Teale, W. H., \& Paciga, K. A. (2014). Assessing vocabulary learning in early childhood. Journal of Early Childhood Literacy, 14(4), 459-481.

Kamil, M. L., \& Hiebert, E. H. (2005). Teaching and learning vocabulary. Teaching and learning vocabulary: Bringing research to practice, 1.

Laufer, B. (1990a). Ease and difficulty in vocabulary learning: Some teaching implications. Foreign Language Annals, 23(2), 147-155.

Laufer, B. (1990b). Why are some words more difficult than others?-Some intralexical factors that affect the learning of words. IRAL-International Review of Applied Linguistics in Language Teaching, 28(4), 293-308.

Leung, C. B., Silverman, R., Nandakumar, R., Qian, X., \& Hines, S. (2011). A comparison of difficulty levels of vocabulary in first grade basal readers for 
preschool dual language learners and monolingual English learners. American Educational Research Journal, 48(2), 421-461.

Loftus, S. M., \& Coyne, M. D. (2013). Vocabulary instruction within a multi-tier approach. Reading \& Writing Quarterly, 29(1), 4-19.

Loftus, S. M., Coyne, M. D., McCoach, D. B., Zipoli, R., \& Pullen, P. C. (2010). Effects of a supplemental vocabulary intervention on the word knowledge of kindergarten students at risk for language and literacy difficulties. Learning Disabilities Research \& Practice, 25(3), 124-136.

Lotto, L., \& De Groot, A. (1998). Effects of learning method and word type on acquiring vocabulary in an unfamiliar language. Language learning, 48(1), 3169.

Maguire, M.J., Hirsh-Pasek, K., \& Golinkoff, R.M. (2006). A unified theory of word learning: putting verb acquisition in context. In K. Hirsh-Pasek \& R.M. Golinkoff (Eds.), Action meets word: How children learn verbs (pp. 364-391). New York: Oxford University Press.

McDonough, C., Song, L., Hirsh-Pasek, K., Golinkoff, R. M., \& Lannon, R. (2011). An image is worth a thousand words: Why nouns tend to dominate verbs in early word learning. Developmental science, 14(2), 181-189.

McKeown, M. G., Beck, I. L., \& Sandora, C. (2012). Direct and rich vocabulary instruction needs to start early. Vocabulary instruction: Research to practice, 2, 17-33. 
Muncer, S. J., Knight, D., \& Adams, J. W. (2014). Bigram frequency, number of syllables and morphemes and their effects on lexical decision and word naming. Journal of psycholinguistic research, 43(3), 241-254.

Murdock Jr, B. B. (1962). The serial position effect of free recall. Journal of experimental psychology, 64(5), 482.

Nagy, W. E., \& Scott, J. A. (2000). Vocabulary processes. In M. L. Kamil, P.B. Mosenthal, P.D. Pearson, \& R. Barr (Eds.), Handbook of reading research (Vol. 3, pp. 269-284). Mahwah, NJ: Lawrence Erlbaum Associates.

Nation, I. S. P. (2001). Learning vocabulary in another language. Cambridge, UK: Cambridge University Press.

National Reading Panel. (2000). Teaching children to read: An evidence-based assessment of the scientific research literature on reading and its implications for reading instruction: Reports of the subgroups. Bethesda, MD: National Institute of Child Health and Human Development.

Paivio, A., Yuille, J. C., \& Madigan, S. A. (1968). Concreteness, imagery, and meaningfulness values for 925 nouns. Journal of experimental psychology, $76(1), 1$.

Penno, J. F., Wilkinson, I. A., \& Moore, D. W. (2002). Vocabulary acquisition from teacher explanation and repeated listening to stories: Do they overcome the Matthew effect?. Journal of Educational Psychology, 94(1), 23.

Pullen, P. C., Tuckwiller, E. D., Konold, T. R., Maynard, K. L., \& Coyne, M. D. (2010). A tiered intervention model for early vocabulary instruction: The effects 
of tiered instruction for young students at risk for reading disability. Learning Disabilities Research \& Practice, 25(3), 110-123.

Robbins, C., \& Ehri, L. C. (1994). Reading storybooks to kindergartners helps them learn new vocabulary words. Journal of educational psychology, 86(1), 54.

Scarborough, H. (2001). Connecting early language and literacy to later reading (dis)abilities: Evidence, theory, and practice. In Neuman and Dickinson, Handbook of Early Literacy Research, pgs. 97-110.

Snow, C. E., Burns, M. S., \& Griffin, P. (1998). Preventing reading difficulties in young children. Washington, DC: National Research Council.

Stahl, S. A. (1991). Beyond the instrumentalist hypothesis: Some relationships between word meanings and comprehension. In P. J. Schwanenflugel (Ed.), The psychology of word meanings. Hillsdale, NJ; Lawrence Erlbaum Associates.

Stahl, S. A., \& Fairbanks, M. M. (1986). The effects of vocabulary instruction: A model-based meta-analysis. Review of educational research, 56(1), 72-110.

Stahl, S. A., \& Nagy, W. E. (2006). Teaching word meanings. New York, NY: Routledge.

Stahl, S. A., \& Shiel, T. G. (1992). Teaching meaning vocabulary: Productive approaches for poor readers. Reading and Writing Quarterly: Overcoming Learning Difficulties, 8(2), 223-241.

Stanovich, K. E. (1986). Matthew effects in reading: Some consequences of individual differences in the acquisition of literacy. Reading research quarterly, 360-407.

Stanovich, K. E., Cunningham, A. E., \& Feeman, D. J. (1984). Intelligence, cognitive skills, and early reading progress. Reading Research Quarterly, 278-303. 
Streefkerk, B. M. (2002). Prominence. Acoustic and lexical/syntactic correlates. LOT.

Subban, P. (2006). Differentiated instruction: A research basis. International education journal, 7(7), 935-947.

Tamayo, J. M. (1987). Frequency of use as a measure of word difficulty in bilingual vocabulary test construction and translation. Educational and Psychological Measurement, 47(4), 893-902.

Tannenbaum, K. R., Torgesen, J. K., \& Wagner, R. K. (2006). The relationships between word knowledge and reading comprehension in third-grade children. Scientific Studies of Reading, 10(4), 381-398.

Wanzek, J. (2016). Building Word Knowledge. Reading \& Writing Quarterly, 30(2).

Weisberg, D. S., Ilgaz, H., Hirsh-Pasek, K., Golinkoff, R., Nicolopoulou, A., \& Dickinson, D. K. (2015). Shovels and swords: How realistic and fantastical themes affect children's word learning. Cognitive Development, 35, 1-14.

Wells, G. (1986). The meaning makers: Children learning language and using language to learn. Portsmouth, NH: Heinemann Educational Books Inc.

Williams, K. T. (2006). Expressive vocabulary test-second edition. Circle Pines, MN: American Guidance Services.

Wright, T. S., \& Neuman, S. B. (2013). Vocabulary instruction in commonly used kindergarten core reading curricula. The Elementary School Journal, 113(3), $386-408$.

Wright, T. S., \& Neuman, S. B. (2014). Paucity and disparity in kindergarten oral vocabulary instruction. Journal of Literacy Research, 46(3), 330-357. 
Zeno, S. M., Ivens, S. H., Millard, R. T., \& Duvvuri, R. (1995). The educator's word frequency guide/Touchstone Applied Science Associates. Inc, Brewster, NY. 